\title{
Article \\ Analysis of Fine Crack Images Using Image Processing Technique and High-Resolution Camera
}

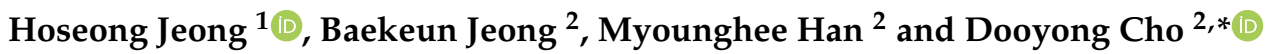 \\ 1 Institution of Agricultural Science, Chungnam National University, 99 Daehak-ro, Daejeon 34134, Korea; \\ hsjeong@cnu.ac.kr \\ 2 Department of Convergence System Engineering, Chungnam National University, 99 Daehak-ro, \\ Daejeon 34134, Korea; bridgeworld@naver.com (B.J.); mhhan73@gmail.com (M.H.) \\ * Correspondence: dooyongcho@cnu.ac.kr; Tel.: +82-42-821-5693
}

Citation: Jeong, H.; Jeong, B.; Han, M.; Cho, D. Analysis of Fine Crack Images Using Image Processing Technique and High-Resolution Camera. Appl. Sci. 2021, 11, 9714. https://doi.org/10.3390/ app11209714

Academic Editors: Jerzy Hoła and Łukasz Sadowski

Received: 12 August 2021

Accepted: 15 October 2021

Published: 18 October 2021

Publisher's Note: MDPI stays neutral with regard to jurisdictional claims in published maps and institutional affiliations.

Copyright: (c) 2021 by the authors. Licensee MDPI, Basel, Switzerland. This article is an open access article distributed under the terms and conditions of the Creative Commons Attribution (CC BY) license (https:// creativecommons.org/licenses/by/ $4.0 /)$.

\section{Featured Application: Analysis of Fine Cracks.}

\begin{abstract}
Visual inspections are performed to investigate cracks in concrete infrastructure. These activities require manpower or equipment such as articulated ladders. Additionally, there are health and safety issues because some structures have low accessibility. To deal with these problems, crack measurement with digital images and digital image processing (DIP) techniques have been adopted in various studies. The objective of this experimental study is to evaluate the optical limit of digital camera lenses as working distance increases. Three different lenses and two digital cameras were used to capture images of lines ranging from 0.1 to $0.5 \mathrm{~mm}$ in thickness. As a result of the experiments, it was found that many elements affect width measurement. However, crack width measurement is dependent on the measured pixel values. To accurately measure width, the measured pixel values must be in decimal units, but that is theoretically impossible. According to the results, in the case of $0.3 \mathrm{~mm}$ wide or wider cracks, a working distance of $1 \mathrm{~m}$ was secured when the focal length was $50 \mathrm{~mm}$, and working distances of $3 \mathrm{~m}$ and $4 \mathrm{~m}$ were secured when the focal length was $100 \mathrm{~mm}$ and $135 \mathrm{~mm}$, respectively. However, for cracks not wider than $0.1 \mathrm{~mm}$, focal lengths of $100 \mathrm{~mm}$ and $135 \mathrm{~mm}$ showed measurability within $1 \mathrm{~m}$, but a focal length of $50 \mathrm{~mm}$ was judged to hardly enable measurement except for certain working positions. Field measurement tests were conducted to verify measurement parameters identified by the results of the indoor experiment. The widths of actual cracks were measured through visual inspection and used for the analysis. From the evaluation, it was confirmed that the number of pixels corresponding to the working distance had a great influence on crack width measurement accuracy when using image processing. Therefore, the optimal distance and measurement guidelines required for the measurement of the size of certain objects was presented for the imaging equipment and optical equipment applied in this study.
\end{abstract}

Keywords: crack measurement; image processing; high resolution; working distance; crack width; visual inspection; structure state assessment; ground sample distance (GSD)

\section{Introduction}

Structures undergo deterioration and damage over time due to various external forces and environmental factors. Among this damage, cracks are indicators that inform us about the current state of structures well. Cracks are usually measured by visual inspection using manpower.

Structures that cannot be easily accessed, such as civil engineering structures, are inspected by manpower using equipment (such as articulated ladders). The difficulty in finding cracks during inspections and the input of professional manpower increases costs and requires large amounts of time. Furthermore, in the case of the lower part of a bridge, nuclear power plant facilities, and dams, which are poorly accessible, it is hard to 
secure stability because workers have to deal with poor work environments. Moreover, there are problems such as poor objectivity and errors occurring in the detection of defects due to the worker's subjective evaluation depending on their working hours, experience, personal ability, and environmental factors. In addition, for the efficient maintenance of structures, preventive maintenance is required with timely repair and reinforcement rather than one-time, large-scale reinforcement. However, frequent inspections are difficult due to limited maintenance budgets, and this makes preventive maintenance difficult.

To remedy the above-mentioned problems, digital image processing (DIP) technologies using imaging equipment have been introduced, and various crack detection algorithms have been developed over the past several decades [1-3]. These technologies are expected to minimize the subjective evaluation of inspectors, thereby securing the objectivity of inspection results, and to relieve constraints on inspection timing and location, as well as solve problems such as the large manpower and cost required for existing inspections and investigations [4]. However, early studies using imaging equipment and image processing techniques used simple image processing technologies or were limited to crack information extraction techniques and had limitations in the measurement of the characteristic information (width, length, shape, etc.) of cracks due to low resolution. Early studies on image processing were mainly those that installed charge-coupled device (CCD) cameras [5], ground penetration radar (GPR), laser systems (LS), or hybrid systems (HS) $[6,7]$, which are classified as non-contact evaluation equipment, on a vehicle such as a van to develop image recognition equipment and equipment that inspects and measures cracks on road surfaces [8]. In related studies on image processing techniques such as ones that applied the Otsu method [9], which is based on shooting variables and threshold value settings, to concrete structures such as roads, tunnels, and bridges to detect and measure cracks [10-13], image preprocessing studies have been conducted using histograms, mean values, median values, and Gaussian filters. Studies on feature extraction using morphology techniques [14-16] and studies on contour detection through primary and secondary differentiation $[17,18]$ have also been conducted and repeatedly developed. Thereafter, the field of applicable target structures in studies conducted on crack detection was expanded to include bridges, tunnels, and dams that cannot be easily accessed.

The enhancement of the resolution of imaging equipment and the development of optical equipment has enabled the detection of cracks from long distances, which has led to studies on crack measurement. In 2012, Lee detected cracks in structures and measured the widths, lengths, and directions of the cracks using an 18-megapixel camera and a $600 \mathrm{~mm}$ lens, and concluded that $0.2 \mathrm{~mm}$ cracks can be detected at a working distance of $40 \mathrm{~m}$ [19]. In 2014, Li secured a working distance of $60 \mathrm{~m}$ in a study that applied a focal length of $1000 \mathrm{~mm}$ using a 20-megapixel video camera, a $500 \mathrm{~mm}$ lens, and a 2X converter, and showed an error rate of $92.6 \%$ [20]. Jahanshahi measured virtual images of 0.4 to $2.0 \mathrm{~mm}$ wide cracks using a 17-megapixel imaging device while changing the working distance from 725 to $1760 \mathrm{~mm}$. He analyzed the filmed images and reported that increases in the working distance led to increases in the ground sample distance (GSD) of the images, that the accuracy of crack width measurement decreased as the number of pixels representing cracks decreased, and that to enhance the accuracy of crack measurement, the working distance should be reduced, the focal length should be increased, and the resolution should be enhanced $[21,22]$. Lins proposed a crack detection and measurement algorithm to automatically measure cracks and measured the crack widths of experimental subjects and actual structures. The measured crack sizes ranged from $1.22 \mathrm{~mm}$ to $30 \mathrm{~mm}$ and error rates of $7-8 \%$ were shown [23]. Khalili used 12-megapixel imaging equipment to measure $15.1 \mathrm{~mm}$ long cracks. He proposed a morphological operator-based algorithm and made efforts to reduce measurement errors [24]. Most crack measurement studies in the past dealt with cracks greater than $0.5 \mathrm{~mm}$, and studies on microcracks smaller than $0.3 \mathrm{~mm}$ have been limited.

Recently, studies that linked unmanned aerial vehicles (UAV) [25,26] with machinelearning-based image processing methods such as neural networks $[27,28]$ to detect or 
measure cracks in concrete structures have been steadily increasing. Various kinds of imaging equipment are applied according to the operational limits of unmanned aerial vehicles. To acquire crack information, the pixel size of the video image according to the working distance must be known. However, the resolution of imaging equipment and optical equipment mounted on general unmanned aerial vehicles and the precision of GPS cause limitations in acquiring crack information, and related studies are insufficient.

In this paper, an indoor measurement experiment was conducted to measure cracks in concrete structures and present guidelines for the image acquisition and processing of imaging equipment. Two units of DSLR video equipment, which is applied in various fields, were selected, and both were equipped with full-frame image sensors. In addition, the focal length was changed using $50 \mathrm{~mm}, 100 \mathrm{~mm}$, and $135 \mathrm{~mm}$ lenses. In order to derive the crack measurement limits and optimal working distances of the selected imaging equipment and optical equipment to analyze precision according to differences in resolution, shooting was conducted while changing the working distance at intervals of $10 \mathrm{~mm}$. In the experiment, virtual images equivalent to microcracks not larger than $0.3 \mathrm{~mm}$ were fabricated, and the images were acquired. The pixel values of these images were measured with Otsu's image processing technique through a preprocessing process, and the areas of the virtual images were obtained by applying the GSD values according to the working distance. The effects of the pixel values measured through the respective imaging equipment and optical equipment on the measurement of crack width were analyzed with theoretical and experimental approaches.

\section{Geometric Relationships of Image Acquisition}

Measurement methods using imaging equipment measure the sizes of objects in an image coordinate system by analyzing the correlation between the size of the real object and the image. Therefore, every measurement unit has the characteristic of having pixel units constituting an image. Measurement methods using acquired images require a process of converting the measured pixel value into an engineering unit.

As can be seen in Figure 1, image acquisition applies the general lens principle. A digital camera uses an image sensor such as a charge-coupled device (CCD) or a complementary metal-oxide-semiconductor (CMOS). It shows the relationship between the object plane that shows the object and the image plane that shows the image based on the image sensor in the camera. Here, the relationship between the captured image and the real object is determined using the ratio of the distance $(O)$ from the measured object to the center point of the lens to the distance $(i)$ from the camera lens to the surface of the image sensor, or the measured value in pixel units can be converted into actual length units by using the number of pixels $(l)$ of the image that corresponds to the actual size $(L)$ of the object.

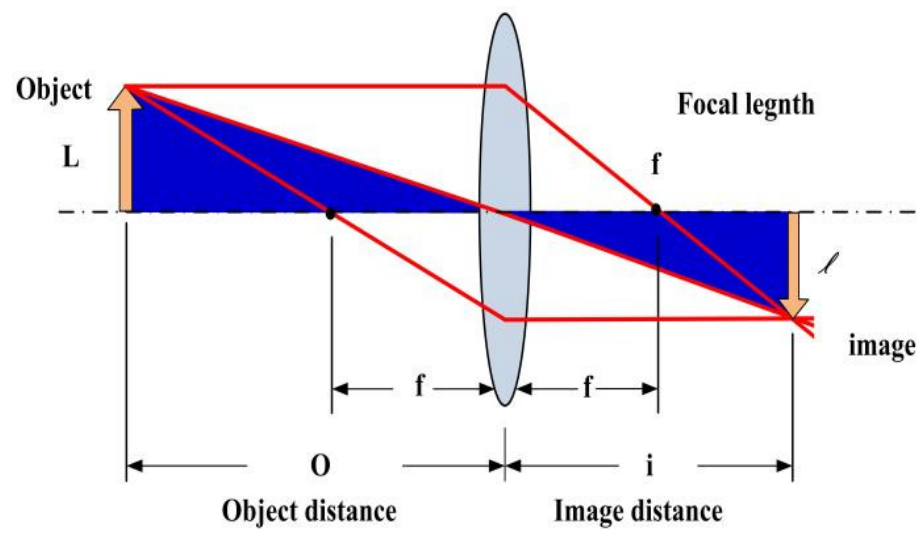

Figure 1. The principle of a thin lens.

Ground sample distance (GSD) or ground resolution refers to the size of one pixel corresponding to the actual size of the object. The unit used for the foregoing is $\mathrm{mm} / \mathrm{pixel}$, and 
it can be obtained using the size and resolution of the camera sensor, the focal length of the lens, and the working distance. The distance conversion coefficient GSD can be generalized through the lens principle from previous researchers and the Gaussian imaging equation.

The Gaussian imaging equation is as shown in Equation (1), and Equation (2) below can be obtained through the geometric relationship between the size of the object, the number of pixels in the image, the distance from the lens to the object, and the distance from the lens to the image.

$$
\begin{gathered}
\frac{1}{O}+\frac{1}{i}=\frac{1}{f} \\
L=\frac{O-f}{f} \times l
\end{gathered}
$$

where $O$ is the distance $(\mathrm{mm})$ from the lens to the object, which is the working distance; $i$ is the distance $(\mathrm{mm})$ from the lens to the image sensor; $f$ is the length $(\mathrm{mm}) ; L$ is the size $(\mathrm{mm})$ of the object; and $l$ is the number of pixels in the image corresponding to the object.

When an object is photographed using a camera, an image of the object is formed on the image sensor. In this case, the size of the object varies according to the size and resolution of the image sensor. This can be defined as the image-forming principle and is illustrated in Figure 2. The size of the image sensor is shown as $w \times h(\mathrm{~mm})$, and the resolution is expressed as $W_{r e} \times H_{r e}$ (pixels).

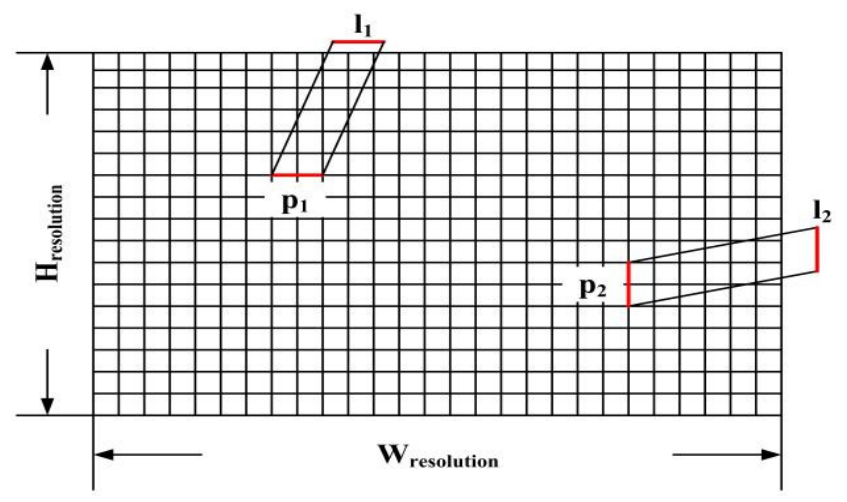

Figure 2. Image-forming principle of the sensor.

In this case, when the number of measured pixels is expressed as $p_{1}$, and the corresponding image length is denoted as $l_{1}$, the following Equation (3) can be obtained from the correlation between the horizontal and vertical sizes of the image sensor and the resolution.

$$
\frac{W}{w}=\frac{p_{1}}{l_{1}} \text { or } \frac{H}{h}=\frac{p_{2}}{l_{2}}
$$

where $W$ and $H$ are the horizontal and vertical resolution values (pixels) of the sensor and $w$ and $h$ are the horizontal and vertical dimensions $(\mathrm{mm})$ of the sensor. If Equation (3) is substituted into Equation (2), vertical or horizontal length is defined as Equation (4) below.

$$
L=\frac{O-f}{f} \times \frac{w \times p_{1}}{W}
$$

Basically, since one pixel is a square, the value of the size does not change according to the direction. Therefore, there is no need to use the values for different directions separately. Equation (4) is an equation for crack measurement and can be changed and expressed as shown by the following Equation (5).

$$
G S D=\frac{L-f}{f} \times \frac{S_{s}}{S_{R}}, C W(\text { crack width })=G S D \times N_{m}
$$


where $L$ is working distance, $f$ is the focal length, $S_{s}$ is the horizontal or vertical dimensions $(\mathrm{mm})$ of the sensor, and $S_{R}$ is the horizontal or vertical resolution values (pixels) of the sensor. $C W$ is the crack width, GSD is the ground sample distance, and $N_{m}$ is the number of measured pixels.

\section{Width Measurement Using Image Processing}

\subsection{Overview of Indoor Measurement Experiments}

\subsubsection{Virtual Image Production and Measurement Experimental Variables}

Cracks occur in structures over time due to various external forces and structural and environmental factors, and vary widely in width, length, and shape. In order to properly measure a crack, the pixel value of the video image must correspond to the value of the actual crack width. Therefore, in this experiment, linear virtual images were produced to substitute for the sizes of microcracks. As can be seen in Figure 3, the images were produced to improve the contrast between the lines and the background, and the lines were produced in $0.1,0.3$, and $0.5 \mathrm{~mm}$ widths. As experimental measurement variables, the pixel values and widths of each virtual image were measured according to the differences in the resolution of the imaging equipment at the same focal length and changes in the focal length at the same resolution of the imaging equipment, as shown in Table 1.

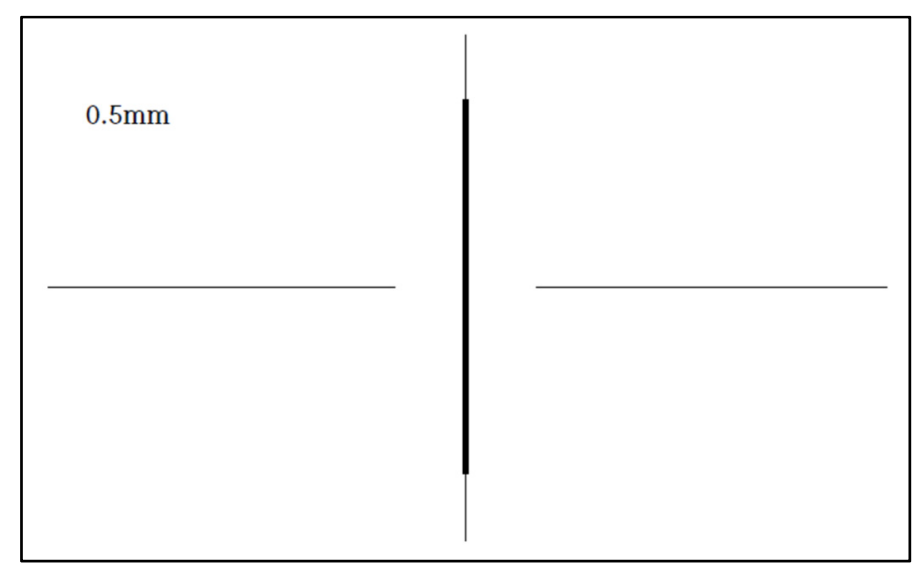

Figure 3. Test image.

Table 1. Measurement experimental variables.

\begin{tabular}{ccccc}
\hline Trial & Manufacturer & Focal Length $(\mathrm{mm})$ & Width $(\mathrm{mm})$ & Resolution (million) \\
\hline CC50 & Canon & 50 & & 22.1 \\
SC50 & & 50 & $0.1,0.3$, and 0.5 & 61.0 \\
SC100 & Sony & 100 & & \\
SC135 & & 135 & \\
\hline$\frac{\mathrm{OC}}{(1)} \frac{\mathrm{OO}}{(2)}-\frac{\mathrm{OO}}{(3)}$ & & \\
& (1) & CC: Canon Camera; SC: Sony camera & \\
& (2) & Focal length & \\
& (3) & Value of width & \\
\hline
\end{tabular}

\subsubsection{Crack Measurement Limits}

In many countries, the standard for the assessment of states regarding crack widths is stipulated as $0.5 \mathrm{~mm}$ or smaller for the prevention of corrosion, the improvement of durability, and aesthetic reasons. ACI-318 regulations stipulate the standard as $0.41 \mathrm{~mm}$ for indoor exposure, $0.3 \mathrm{~mm}$ for outdoor exposure, and $0.2 \mathrm{~mm}$ for extreme environments. British standards (BS) 8110 stipulate that cracks should not exceed $0.3 \mathrm{~mm}$ in a general environment, and South Korea stipulates five levels of standards for the assessment of states 
regarding the maximum crack widths in visual inspections of various structures. Among them, in the case of grade B, the standards are presented as 0.1 to $0.3 \mathrm{~mm}$ for reinforced concrete and as smaller than $0.2 \mathrm{~mm}$ for prestressed concrete. In this study, the allowable limit for crack width detection and measurement was set to $0.1 \mathrm{~mm}$ to $0.3 \mathrm{~mm}$, and an experimental plan was established for the selection of optimum image measurement equipment and the determination of shooting conditions and image processing techniques, such as the degrees of recognition of cracks according to working distances and the extraction of cracks with limits.

\subsubsection{Image Equipment and Optical Equipment (Lens)}

The most important thing in the use of imaging equipment and the crack measurement system using image processing techniques is selecting a high-definition digital camera. Once the crack measurement limit range has been set, the imaging equipment must be selected in consideration of the camera resolution, sensor size, and shutter speed. The imaging equipment used in this study was Sony's mirrorless A7RIV and Canon's EOS 5D Mark III, which were installed with image sensors in full-frame $35.7 \times 23.8 \mathrm{~mm}^{2}$ and $36 \times 24 \mathrm{~mm}^{2}$ sizes with resolutions of 61 million $(9504 \times 6336)$ and 22.1 million $(5760 \times 3840)$ pixels, respectively.

The lens collects light and sends it to the image sensor, and the working distance is secured according to the specifications of the lens. The types of lenses can be divided into wide-angle, telephoto, standard, and prime. Wide-angle lenses enable shooting wider background ranges compared to standard lenses and shooting large pictures of subjects that cannot be approached from distant locations. Prime lenses are only suitable for either long distances or short distances, thereby minimizing the problems above. The focal length of the lens necessary to satisfy accuracy in the determined working distance range can be obtained by using Equation (5). Figure 4 below shows the focal lengths according to the working distances necessary to acquire the size of the subject clearly and accurately. In this study, lenses that can optimize the performance of digital high-definition cameras were selected. The applied lenses consisted of 50,100, and $135 \mathrm{~mm}$ single-vision lenses selected according to manufacturer, and the specifications of the lenses are shown in Table 2. As for the range of the final working distances, the distances to the points where the values of the size of one pixel corresponding to individual line widths become the same were set as the measurement limit distances.

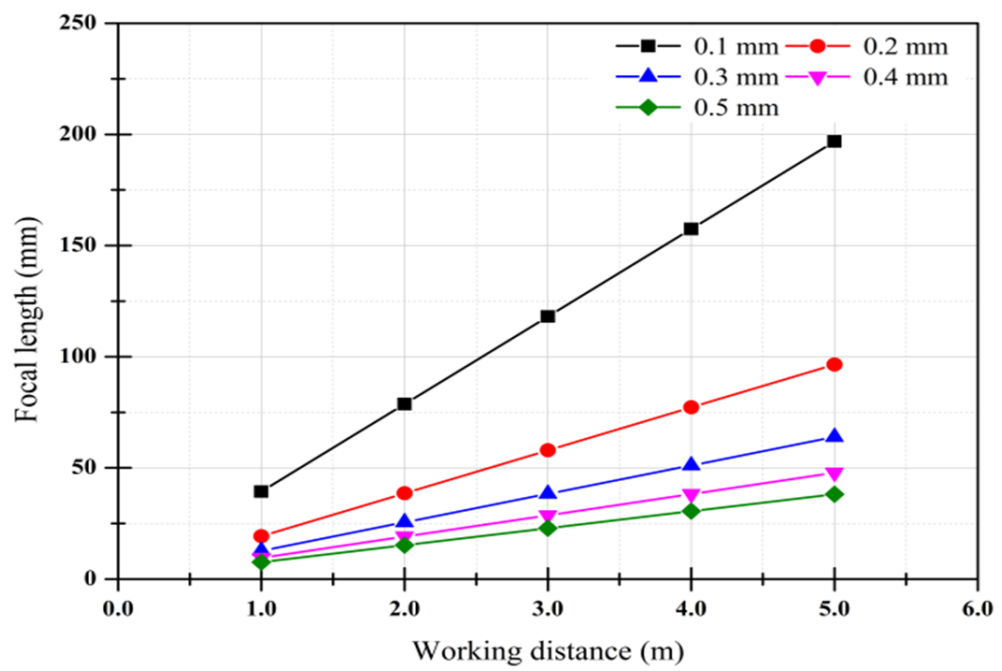

Figure 4. Focal length satisfying width measurement. 
Table 2. Lens specification.

\begin{tabular}{|c|c|c|c|c|}
\hline \multirow[b]{2}{*}{ Classification } & \multicolumn{3}{|c|}{ Sony } & \multirow{2}{*}{$\frac{\text { Canon }}{\text { 的 }}$} \\
\hline & & & & \\
\hline Focal length & $50 \mathrm{~mm}$ & $100 \mathrm{~mm}$ & $135 \mathrm{~mm}$ & $50 \mathrm{~mm}$ \\
\hline $\begin{array}{l}\text { Min. focus } \\
\text { distance }\end{array}$ & $0.45 \mathrm{~m}$ & $\begin{array}{c}0.57 \mathrm{~m}(0.57-1 \mathrm{~m}) \\
0.85 \mathrm{~m}(0.85-\infty \\
\mathrm{m})\end{array}$ & $0.7 \mathrm{~m}$ & $0.35 \mathrm{~m}$ \\
\hline Weight & $778 \mathrm{~g}$ & $700 \mathrm{~g}$ & $950 \mathrm{~g}$ & $160 \mathrm{~g}$ \\
\hline Angle of view & $47^{\circ}$ & $24^{\circ}$ & $18^{\circ}$ & $46^{\circ}$ \\
\hline
\end{tabular}

\subsection{Image Acquisition}

Imaging equipment, such as a camera, reacts sensitively to the amount of light. Good images can be obtained by adjusting the amount of light to the optimum by changing the aperture value or shutter speed value. However, with regard to filming outdoors, it is very difficult to secure images of consistent quality because the amount of light changes from moment to moment due to the weather, environmental conditions, and sunlight. In addition, not only does the brightness of a video image vary depending on the direction of light, but shadows may also be misprocessed as cracks during image processing because of geographic conditions present in the image. To remove the factors that cause errors in advance and keep the image quality consistent, an indoor experiment was conducted under LED lighting. The average illuminance of the LED lights in the laboratory was measured using a portable illuminance meter and was determined to be 1455 lux.

There were five image shooting methods: fully automatic shooting, shutter priority, aperture priority, program auto, and manual exposure modes. In the case of the fully automatic shooting mode, everything in the camera is set to automatic, and as for shutter and aperture priority-based modes, the shutter and aperture are adjusted to obtain an exposure value that corresponds to the brightness of the subject. In general, whereas the shutter speed is adjusted when shooting dynamic images, an aperture priority-based shooting method is used when shooting static images. In this experiment, an aperture priority-based shooting method was used to obtain clear video images. As can be seen in Figure 5, when the aperture value is low, the foreground part in focus is clear, but the background is blurred, and when the aperture value is high, the overall video image is clear.

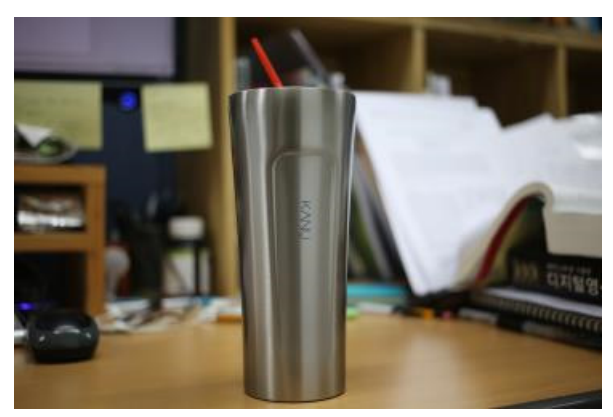

(a) Value of aperture: 2.8

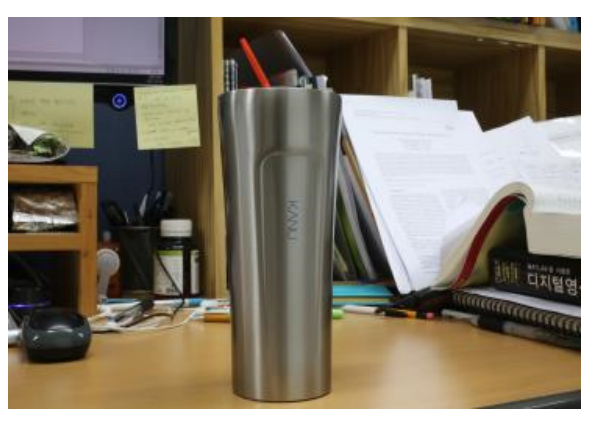

(b) Value of aperture: 22

Figure 5. Experiment condition.

The working distance was measured by measuring the distance from the virtual image plane to the position of the camera sensor using an aluminum staff used for level measuring. As can be seen in Figure 6a, the position of the camera sensor is indicated by the focal plane mark, a Saturn-shaped symbol on the top of the camera. Since it was difficult to 
measure the sensor position, a three-axis self-leveling laser was used to match the position of the sensor with the position of the staff scale, and the distance between the virtual image plane and the sensor plane was measured as shown in Figure $6 \mathrm{~b}$. The equipment and working distance measuring method used in the experiment are shown in Figure 6c,d. Feng et al. (2015) conducted numerical studies to quantify the error resulting from camera non-perpendicularity. The range of the optical axis tilt angle was from $0^{\circ}$ to $30^{\circ}$, and they determined that the error increases as the tilt angle increases. However, they discovered that a measurement error of less than $1 \%$ was determined at a 30 degree optical axis tilt angle, and this measurement error is acceptable [29]. Therefore, the orthogonality between the image plane and object surface was not considered in this study. Figure 7 shows an overall view of the indoor measurement experiment, and image shooting was carried out until the final working distance of each linear virtual image was reached, while changing the working distance in units of $10 \mathrm{~mm}$ to acquire the images.

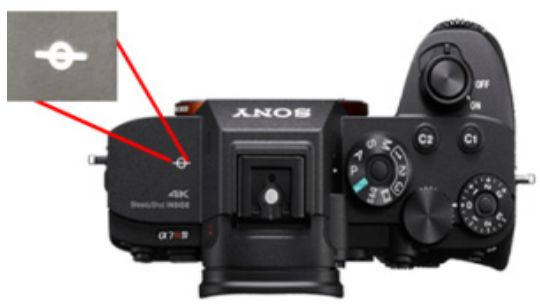

(a) Position of sensor
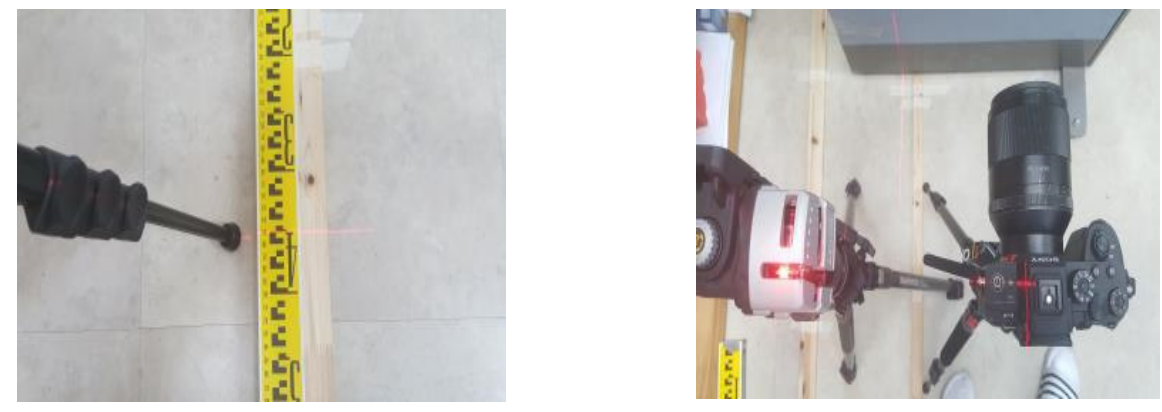

(b) Method of working distance measurement

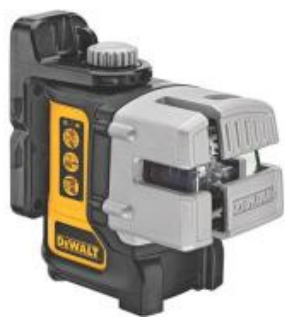

(c) Self-leveling 3-beam laser

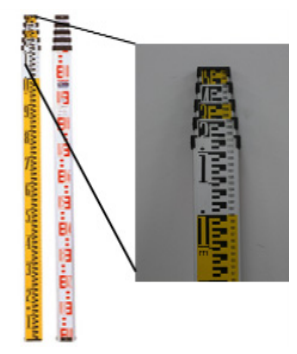

(d) Level staff

Figure 6. Experimental methods and apparatus.

\subsection{Image Processing}

First, for local rather than global image processing of acquired images, regions of interest (ROI) were set, and to make the images in the ROIs clearer, preprocessing processes such as image enhancement and sharpening were carried out. For image processing, the image processing toolbox (IPT) of the Matlab program of Mathworks Co. was used.

The IPT provides a comprehensive set of standard algorithms, functions, applications for image processing, and image processing techniques. Since the linear virtual images used in the indoor experiment have clear contrasts between the linear images and the background, a simple image processing technique was applied to measure the pixel value 
of the line width. As for the applied image processing techniques, color images were first converted into grayscale images, and then the grayscale images were converted into binary images using Otsu's method. Then, pixel values corresponding to the width of the linear virtual images were obtained.

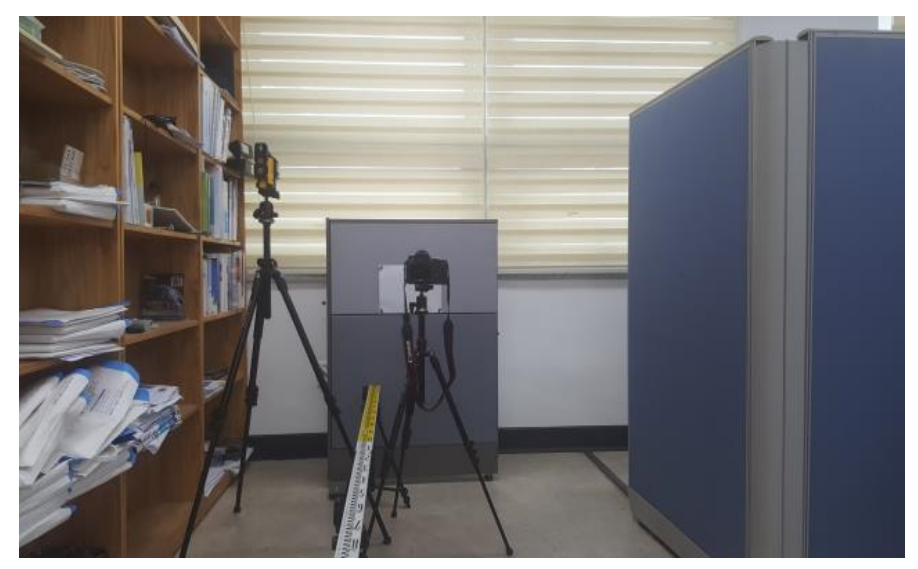

Figure 7. Indoor test setting.

\section{Measurement Results and Analysis}

\subsection{Pixel Values According to Working Distance}

4.1.1. Measured Pixel Values According to Changes in Resolution

To verify the measurement limits of imaging equipment according to differences in resolution, lenses with the same focal length were applied, and lenses suitable for individual manufacturers were applied. As presented above, the names of imaging equipment units were written as SC (Sony camera) and CC (Canon camera) to improve understanding of the study findings and analysis values. The pixel values from the video images acquired using each imaging equipment unit, measured using the Matlab program, are shown in Figures 8 and 9. According to the physical specifications of the applied single-vision lens with a focal length of $50 \mathrm{~mm}$, working distances ranging from the minimum distances of $300 \mathrm{~mm}$ (CC) and $400 \mathrm{~mm}$ (SC) to the working distances at which the pixel sizes become the same as the sizes of the virtual images are shown. A relative comparison was carried out at a working distance of $400 \mathrm{~mm}$, which is the minimum distance of the SC equipment.

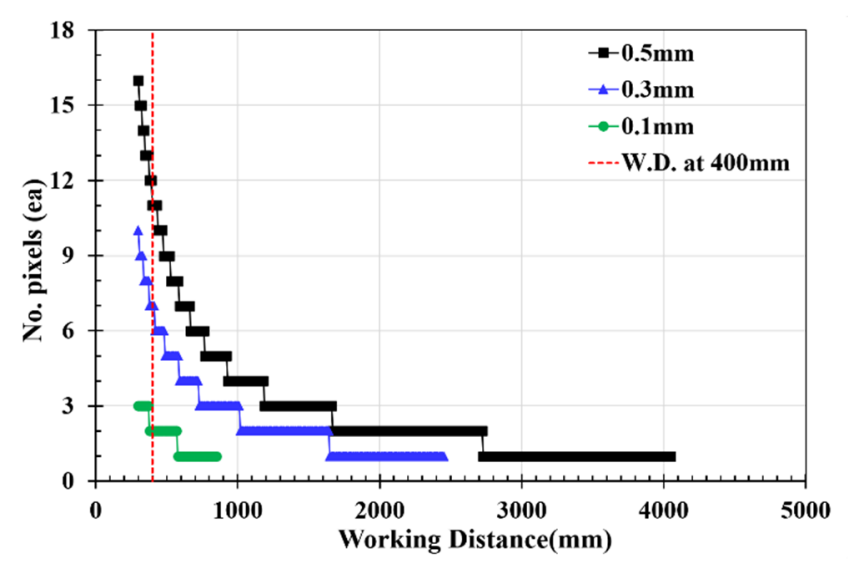

(a) CC using focal length of $50 \mathrm{~mm}$

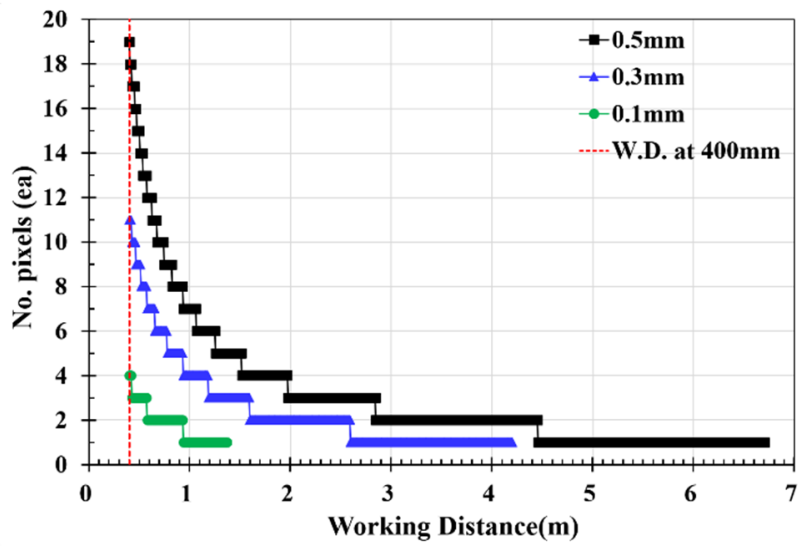

(b) SC using focal length of $50 \mathrm{~mm}$

Figure 8. Results of pixel measurement by each manufacturer. 


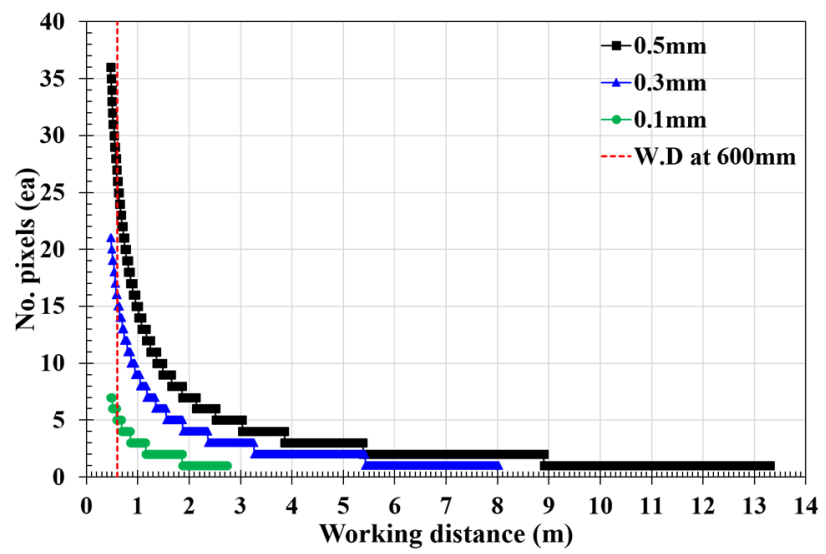

(a) $100 \mathrm{~mm}$ focal length

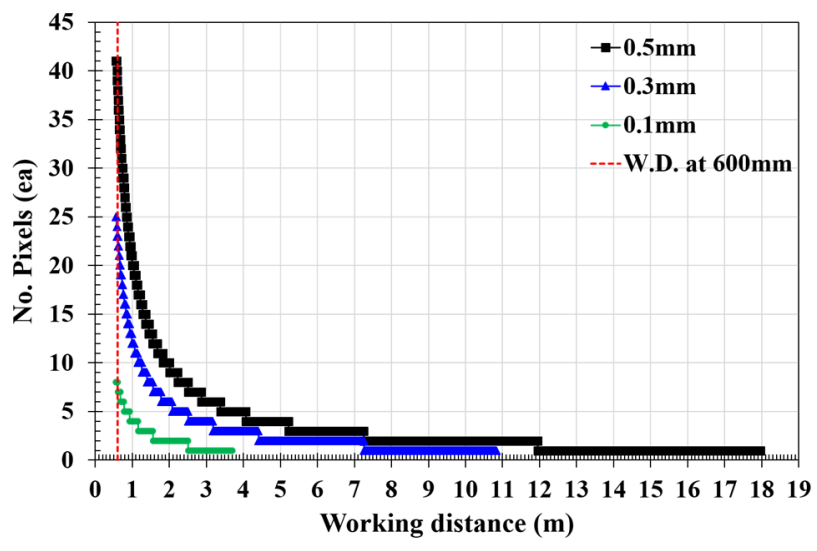

(b) $135 \mathrm{~mm}$ focal length

Figure 9. Results of pixel measurement applying different focal lengths using SC.

The pixel values measured using CC50 and SC50 at a working distance of $400 \mathrm{~mm}$ are shown in Table 3 and Figure 8 . The pixel values measured while the width value increased by five times from $0.1 \mathrm{~mm}$ to $0.5 \mathrm{~mm}$ show a resulting increase by 5.5 times from 2 to 11 in the case of CC, and by 4.75 times from 4 to 19 in the case of SC, at a working distance of $400 \mathrm{~mm}$. When the width value was $0.1 \mathrm{~mm}$, the relevant working distance was $850 \mathrm{~mm}$ in the case of CC and $1370 \mathrm{~mm}$ in the case of SC, with an increase of 1.61 times, and when the width value was $0.3 \mathrm{~mm}$, the relevant working distance increased by 1.63 times from 2450 to $4010 \mathrm{~mm}$, and when the width value was $0.5 \mathrm{~mm}$, the relevant working distance increased by 1.64 times from 4050 to $6650 \mathrm{~mm}$. Therefore, it was confirmed that the number of pixels measured and the limitation of working distance increased dependence on the resolution of the image sensor and the size of the object. Regardless of the proportional relationship for all the variables, it was found that the number of pixels acquired exponentially decreases as the working distance increases. Additionally, the number of pixels at the minimum working distance does not proportionally increase as the physical dimensions of an object increase.

Table 3. The number of pixels measured by resolution differences at $400 \mathrm{~mm}$ working distance.

\begin{tabular}{ccc}
\hline & \multicolumn{3}{c}{ Equivalent Focal Length } \\
\cline { 2 - 3 } Classification & \multicolumn{3}{c}{ Number of Pixels (Each) } \\
\cline { 2 - 3 } & CC50 & SC50 \\
\hline $0.1 \mathrm{~mm}$ & 2 & 4 \\
$0.3 \mathrm{~mm}$ & 8 & 11 \\
$0.5 \mathrm{~mm}$ & 11 & 19 \\
\hline
\end{tabular}

\subsubsection{Measured Pixel Values According to Changes in Focal Length}

In order to identify the measured pixel values according to changes in the focal length, 100 and $135 \mathrm{~mm}$ were applied to the SC equipment as focal lengths, and the results are shown in Figure 9 below. With regard to SC100-0.1, a pixel value of 7 was obtained through measurement at the minimum working distance of $470 \mathrm{~mm}$, and pixel values of 21 and 36 were identified for SC100-0.3 and SC100-0.5, respectively. In the case of SC135-0.1, 0.3, and 0.5 , pixel values of 8,25 , and 41 , respectively, were obtained when measured at the minimum working distance of $565 \mathrm{~mm}$. Relative comparisons with the results for SC50 were carried out. Since the minimum working distance varied depending on the physical characteristics of the lens, the comparisons were carried out at the same working distance of $600 \mathrm{~mm}$. Compared to SC50-0.1, a 2.5 times higher value was obtained for SC100-0.1, and a four times higher value was obtained for SC135-0.1. In the case of a $0.3 \mathrm{~mm}$ virtual image, approximately 2.29 times and 3.57 times higher values were obtained, respectively, 
and with regard to a $0.5 \mathrm{~mm}$ virtual image, approximately 2.16 times and 3.16 times higher values were obtained, as can be seen in Table 4 .

Table 4. The number of pixels measured by focal length changes at a working distance of $600 \mathrm{~mm}$.

\begin{tabular}{cccc}
\hline \multirow{3}{*}{ Classification } & \multicolumn{3}{c}{ Equivalent Resolution } \\
\cline { 2 - 4 } & SC50 & Number of Pixels (Each) \\
\cline { 2 - 4 } & $2(4)$ & SC100 & SC135 \\
\hline $0.1 \mathrm{~mm}$ & $7(11)$ & $5(7)$ & $8(8)$ \\
$0.3 \mathrm{~mm}$ & $12(19)$ & $16(21)$ & $23(25)$ \\
$0.5 \mathrm{~mm}$ & $26(36)$ & $38(41)$ \\
\hline
\end{tabular}

( ) The number of measurement pixels according to each focal length at min. working distance.

\subsection{Measured Values of Line Widths According to Working Distance}

4.2.1. Measured Values of Line Widths according to Differences in the Resolution of Imaging Equipment

As written above, the GSD of the pixel value measured by each variable through image processing was calculated according to the working distance to measure the width value of the virtual image. Figure 10 shows the width values of individual virtual images with the same focal length of $50 \mathrm{~mm}$ applied, measured by working distance using individual units of imaging equipment. Here, the ground truth represents the width value of the actual virtual image, and the shaded part of the red box is the percentage within the limit of error, which is less than 10\% (PWL-10). In addition, the working position where the size of one measured pixel has the same value as the width of the virtual image was expressed as the measurement limit distance of the imaging equipment.

As a result of measurement of the width of CC50-0.1 in Figure 10a, there were 56 working positions within the measurement limit distance of $850 \mathrm{~mm}$, and the number of working positions that had values within PWL-10 was 22, accounting for 39.29\%. However, in the case of SC50-0.1, the number of working positions that had values within PWL-10 was 38, accounting for $38.77 \%$ of the 98 working positions within the measurement limit distance.

With regard to CC50-0.3, the number of working positions within the measurement limit distance of $2450 \mathrm{~mm}$ was 216, and the number of working positions that had values within PWL-10 was 105, which is $48.6 \%$ in ratio. However, for SC50-0.3, the number of working positions that had values within PWL-10 within the measurement limit distance of $4010 \mathrm{~mm}$ was 178 , accounting for $49.2 \%$ of the entire 362 working positions within the measurement limit distance. Here, all working positions were within the working distance of $1 \mathrm{~m}$ except for those at 930 and $940 \mathrm{~mm}$, which had values within PWL-10, and the ratio was $96.7 \%$. Within the working distance of $1.5 \mathrm{~m}$, there were 99 working positions, and the ratio of those working positions that had values within PWL-10 was $89.1 \%$, as can be seen in Figure 10b. The results of the measurement of the width of a $0.5 \mathrm{~mm}$ virtual image are shown in Figure 10c. In the case of CC50-0.5, the ratio of working positions within $1 \mathrm{~m}$ that had values within PWL-10 was 95\%, and it was seen that errors increased as the working distance increased.

For the accumulated shooting section, 376 working positions were identified within the measurement limit distance of $4050 \mathrm{~mm}$, and the number of working positions that had values within PWL-10 was 188 , with a ratio of $50.26 \%$. In the case of SC50-0.5, it was found that the values measured at all working positions in the entire section within a working distance of $1.5 \mathrm{~m}$ corresponded to PWL-10. The number of working positions that had values within PWL-10 within a working distance of $2 \mathrm{~m}$ was 144 out of 161 locations, with a ratio of $89.4 \%$. It was confirmed that the precision showed a tendency to decrease after that, since the shooting section grew as the working distance increased. Within the measurement limit distance of $6650 \mathrm{~mm}, 321$ out of 624 working positions showed values within PWL-10, with an accuracy of $51.3 \%$. Table 5 shows the resulting measurement values of each image with different resolutions for the same focal length. The measurement accuracy increased 
slightly, but this seems to be a result of the increase in the measurement limit distance. For instance, as can be seen in Table 5, in the case of CC50-0.1, the ratio of working positions that had values within PWL-10 was 39.29\% within the limit distance of $850 \mathrm{~mm}$, but in the case of SC50-0.1, the ratio was the same when the same limit distance was applied. In conclusion, it was demonstrated that the SC equipment had 2.76 times higher resolution corresponding to the sensor area and 1.65 times larger horizontal and vertical dimensions than the CC equipment, but no significant difference in measurement accuracy was shown between the two equipment units within their respective limit distances.

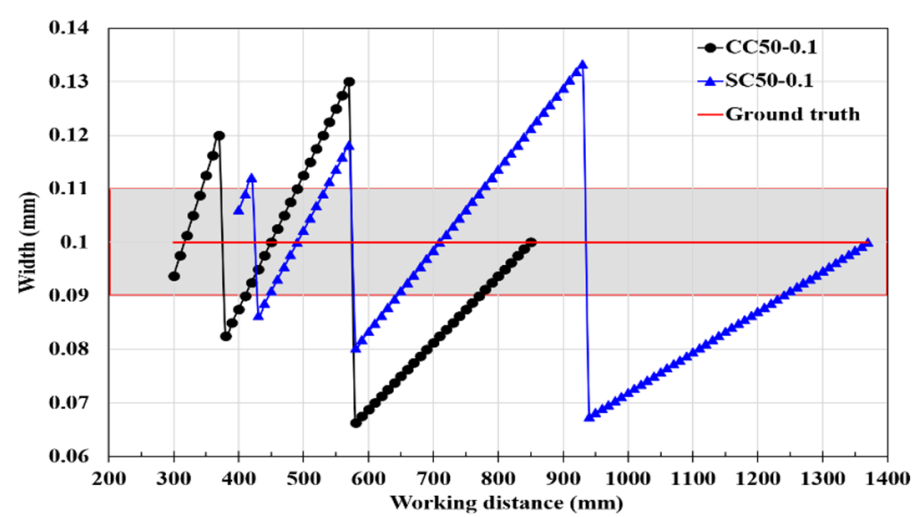

(a) $0.1 \mathrm{~mm}$ line width

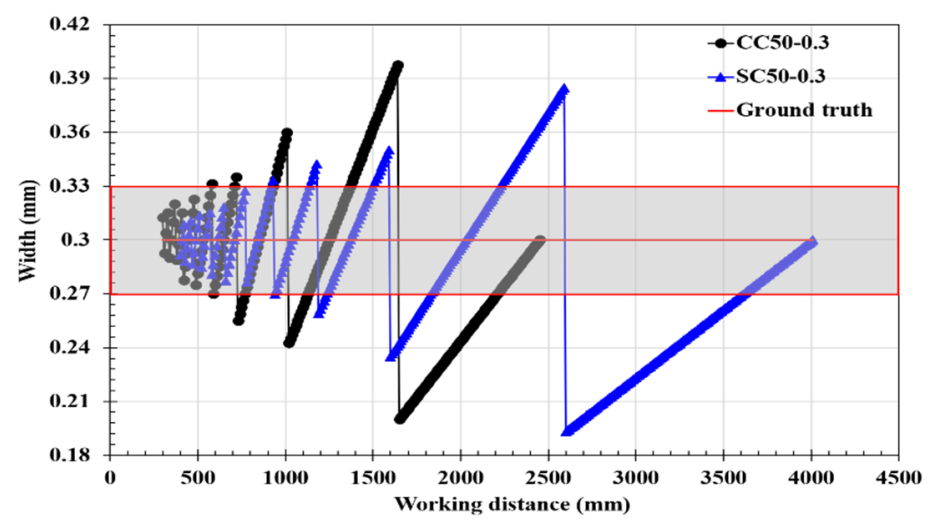

(b) $0.3 \mathrm{~mm}$ line width

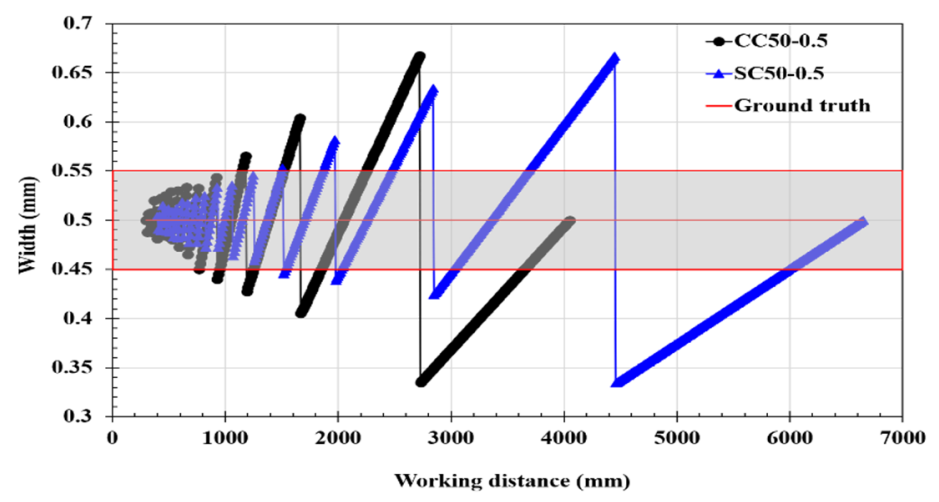

(c) $0.5 \mathrm{~mm}$ line width

Figure 10. Width measurement results of Canon and Sony cameras. 
Table 5. Value of PWL-10 within working distance by resolution difference.

\begin{tabular}{|c|c|c|c|c|c|c|c|}
\hline \multirow{2}{*}{\multicolumn{2}{|c|}{ Classification }} & \multicolumn{5}{|c|}{ PWL-10 } & \multirow{3}{*}{$\begin{array}{l}\text { Unit: \% } \\
0.5 \mathrm{~mm}\end{array}$} \\
\hline & & \multicolumn{3}{|c|}{ SC50 } & \multicolumn{2}{|c|}{ 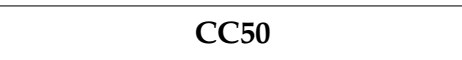 } & \\
\hline & & $0.1 \mathrm{~mm}$ & $0.3 \mathrm{~mm}$ & $0.5 \mathrm{~mm}$ & $0.1 \mathrm{~mm}$ & $0.3 \mathrm{~mm}$ & \\
\hline \multirow{7}{*}{$\begin{array}{c}\text { Working } \\
\text { distance } \\
(\mathrm{m})\end{array}$} & 0.85 & 52.17 & 100 & 100 & 39.29 & 87.71 & 100 \\
\hline & 1.00 & $\begin{array}{c}39.34 \\
(38.77) *\end{array}$ & 96.72 & 100 & & 78.87 & 95.77 \\
\hline & 1.50 & & 89.18 & 100 & & 72.07 & 88.28 \\
\hline & 2.00 & & 72.04 & 89.44 & & $\begin{array}{c}46.11 \\
(48.61) *\end{array}$ & 72.51 \\
\hline & 2.50 & & 65.40 & 89.57 & & & 65.40 \\
\hline & 3.00 & & 52.87 & 72.41 & & & 52.87 \\
\hline & 4.00 & & $\begin{array}{c}49.03 \\
(49.17) *\end{array}$ & $\begin{array}{c}70.63 \\
(51.44) *\end{array}$ & & & $\begin{array}{c}47.92 \\
(50.26)\end{array}$ \\
\hline
\end{tabular}

( ) *alue of PWL-10 at the measurement limit distance.

However, relative comparisons by limit distance and shooting section of the CC equipment showed that the SC equipment had somewhat higher precision, and it was confirmed that the difference in resolution increased working distance as well as accuracy. In addition, it was judged that the size measurement of a specific object is based on the numbers of horizontal and vertical pixels, not the pixel value in the space corresponding to the sensor. At the current level of imaging equipment, when measuring a $0.1 \mathrm{~mm}$ crack by applying a focal length of $50 \mathrm{~mm}$, a minimum working distance from the crack surface is required, and it is judged that crack measurement is somewhat difficult without increasing the resolution and focal length.

4.2.2. Measured Values of Line Widths According to Increases in Focal Length Using the Same Imaging Equipment

Earlier, the resulting measurement values of the widths of virtual images according to differences in resolution at the same focal length of $50 \mathrm{~mm}$ were checked. In this chapter, the widths of virtual images were measured while increasing the focal length at the same resolution, and the resulting values were analyzed.

Figure 11 shows the resulting measurement values of a $0.1 \mathrm{~mm}$ wide virtual image. With regard to SC100-0.1, the number of working positions that had values within PWL10 was 96 out of 218 total working positions within the measurement limit distance of $2740 \mathrm{~mm}$, representing a ratio of $46.49 \%$. As for SC135-0.1, the ratio of working positions that had values within PWL-10 was 95.55\% within a working distance of $1 \mathrm{~m}$, and the ratio decreased as the working distance increased to show values lower than $82.10 \%$ at a working distance of $1.5 \mathrm{~m}$. The ratio showed a tendency to decrease rapidly after that. Within the measurement limit distance of $3700 \mathrm{~mm}, 136$ out of 301 working positions had values within PWL-10, representing a ratio of $47.94 \%$.

In Figure 12, with regard to SC100-0.3, 379 out of 746 working positions within the measurement limit distance of $8020 \mathrm{~mm}$ had values within PWL-10, representing a ratio of $51.45 \%$. In this case, when checked by the shooting section, the measurement accuracy at which all working positions in the entire section, ranging from the minimum working distance to $1.5 \mathrm{~m}$, had values within PWL-10, as shown. However, in the case of SC135-0.3, $100 \%$ measurement accuracy was shown over the entire shooting section within $2 \mathrm{~m}$, and the measurement accuracy gradually decreased afterward as the distance increased so that $97.95 \%$ measurement accuracy was secured within $3 \mathrm{~m}$. The measurement accuracy was $91.01 \%$ at the $4 \mathrm{~m}$ working position and then showed a tendency to decrease from the working position, so the number of working positions that had values within PWL10 became 517 out of 1014 working positions within the measurement limit distance of $10,830 \mathrm{~mm}$, representing a ratio of $51.94 \%$. 


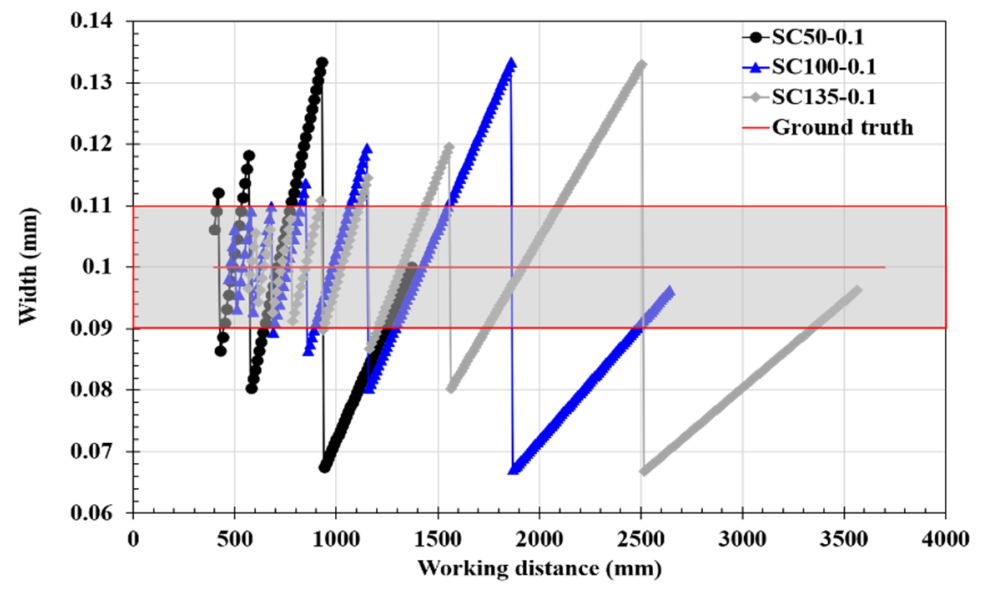

Figure 11. Results of $0.1 \mathrm{~mm}$ width measurement.

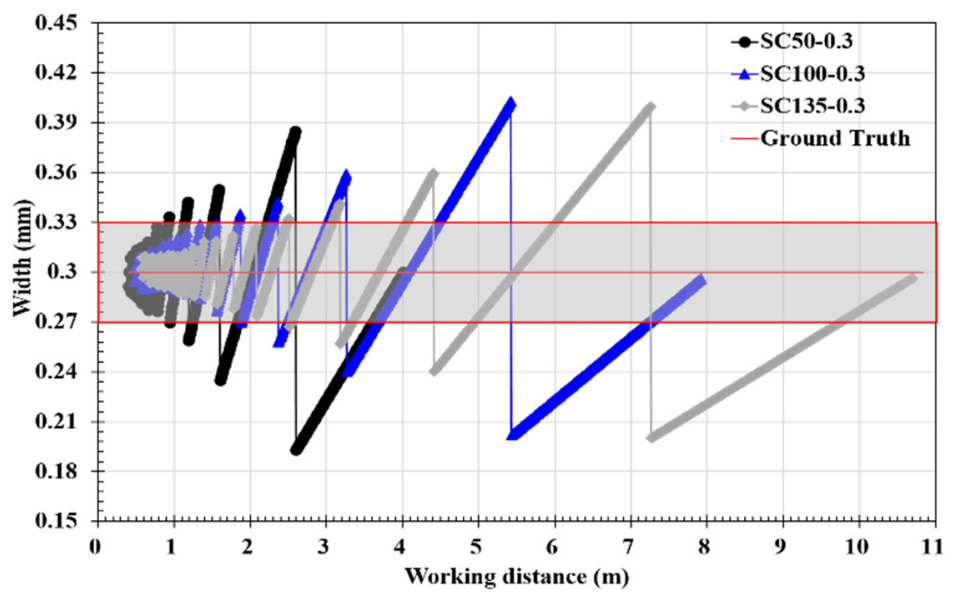

Figure 12. Results of $0.3 \mathrm{~mm}$ width measurement.

In the results of measurement of a $0.5 \mathrm{~mm}$ wide virtual image, in the case of SC100-0.5, 663 out of 1274 working positions within the measurement limit distance of $13,300 \mathrm{~mm}$ had values within PWL-10, representing a ratio of $52.41 \%$, as seen in Figure 13. When checked by the shooting section, it was found that measurement precision was secured over the entire section, from the minimum working distance to $3 \mathrm{~m}$. As for SC135-0.5, all working positions within $4 \mathrm{~m}$ had values within PWL-10, and the precision decreased afterward so that $98.20 \%$ of all working positions within $5 \mathrm{~m}$ had values within PWL-10. The resulting value was $89.49 \%$ in the shooting section within $5.5 \mathrm{~m}$, but the precision increased slightly after that so that $91.26 \%$ of all working positions in the shooting section within $6.5 \mathrm{~m}$ had values within PWL-10. The reason for the slight increase after decreasing is that the number of working positions that had values within PWL-10 remained the same, while the working distance continued to increase. In the shooting section within $7 \mathrm{~m}$, the value was $86.66 \%$, and as the working distance increased, 900 out of 1727 sections within the measurement limit distance of $17,960 \mathrm{~mm}$ had values within PWL-10, representing a ratio of $52.70 \%$. The overall precision seems to have increased slightly compared to SC100-0.5, and the reason is judged to be the fact that not only the maximum shooting section but also the number of working positions that had values within PWL-10 increased. 


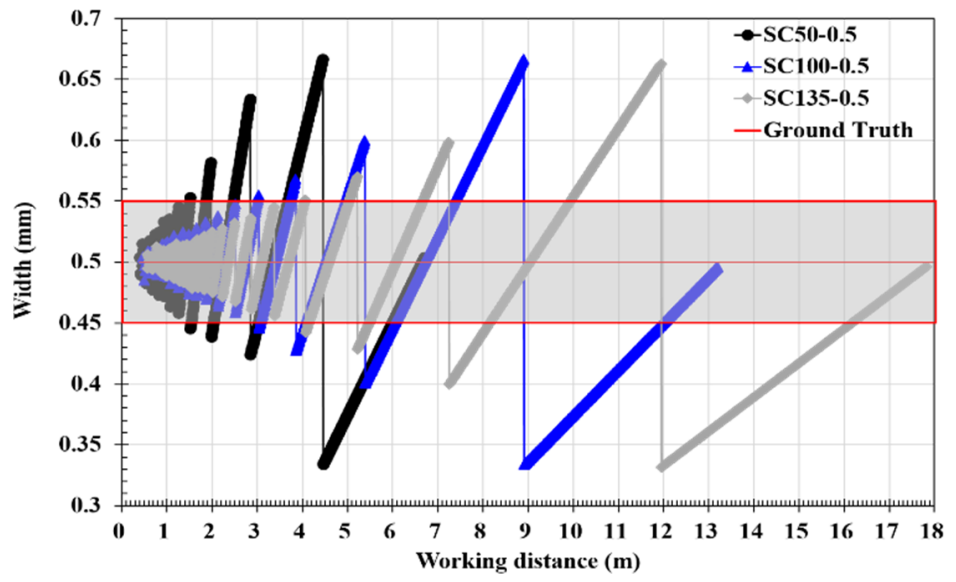

Figure 13. Results of $0.5 \mathrm{~mm}$ width measurement.

The levels of measurement accuracy by shooting section according to changes in focal length are summarized in Figure 14 and Table 6. The resulting values of SC135-0.1 and SC50-0.5, SC100-0.3 and SC50-0.5, and SC135-0.3 and SC100-0.5 show similar trends. It was found that in the case of SC135-0.5, at least 95\% measurement accuracy was secured up to $5 \mathrm{~m}$. For widths smaller than $0.3 \mathrm{~mm}$, which is the crack measurement limit, but not smaller than $0.1 \mathrm{~mm}$, which is the purpose of this study, SC50-0.3, SC100-0.3, and SC135-0.3 secured at least $90 \%$ measurement accuracy within working distances of $1 \mathrm{~m}, 3 \mathrm{~m}$, and $4 \mathrm{~m}$. However, in the case of $0.1 \mathrm{~mm}$ width, at least $85 \%$ and $95 \%$ measurement accuracy levels were secured within a $1 \mathrm{~m}$ working distance at focal lengths of $100 \mathrm{~mm}$ and 135 $\mathrm{mm}$, respectively. However, as mentioned above, it is judged that when measuring $0.1 \mathrm{~mm}$ cracks, if a focal length of $50 \mathrm{~mm}$ is applied, the cracks can hardly be measured except for certain working positions. If microcracks not wider than $0.1 \mathrm{~mm}$ are measured by applying imaging equipment with the same resolution as the one applied in this experiment and a focal length of $50 \mathrm{~mm}$, it is judged that the measurement should be carried out at distances shorter than the minimum working distance from the crack surface. In addition, to secure at least $90 \%$ measurement accuracy within the working distance of $1 \mathrm{~m}, 135 \mathrm{~mm}$ should be applied as the minimum focal length. Furthermore, on estimating the resolution value required when the focal length is $50 \mathrm{~mm}$ using the GSD value with the $135 \mathrm{~mm}$ focal length applied, it is thought that the resolution range of the imaging equipment should have a performance of 400 million pixels.

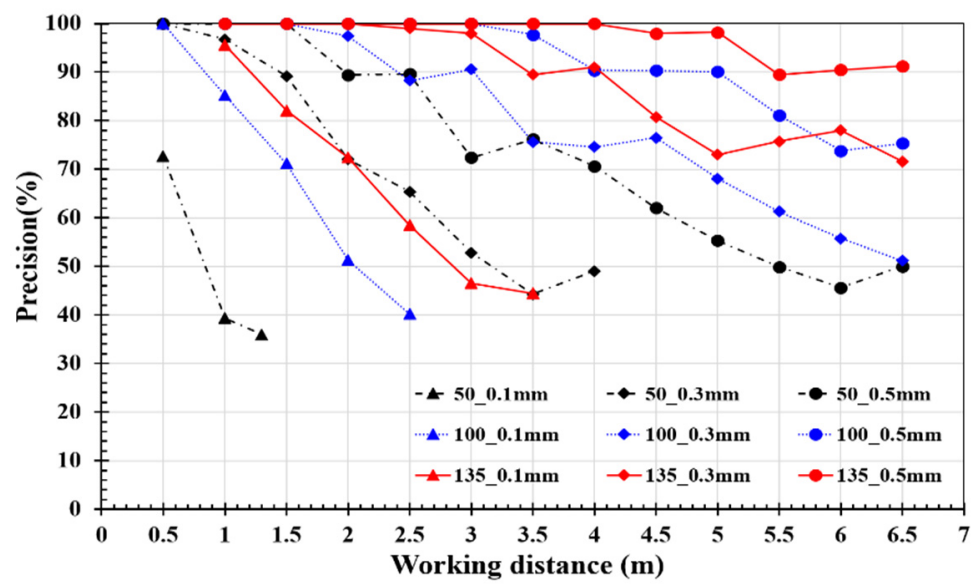

Figure 14. Value of PWL-10 according to focal length difference. 
Table 6. Value of PWL-10 within working distance by focal length difference.

\begin{tabular}{|c|c|c|c|c|c|c|c|}
\hline \multirow{2}{*}{\multicolumn{2}{|c|}{ Classification }} & \multicolumn{5}{|c|}{ PWL-10 } & \multirow{3}{*}{$\begin{array}{l}\text { Unit: \% } \\
0.5 \mathrm{~mm}\end{array}$} \\
\hline & & \multicolumn{3}{|c|}{ SC100 } & \multicolumn{2}{|c|}{ 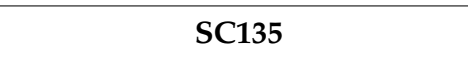 } & \\
\hline & & $0.1 \mathrm{~mm}$ & $0.3 \mathrm{~mm}$ & $0.5 \mathrm{~mm}$ & $0.1 \mathrm{~mm}$ & $0.3 \mathrm{~mm}$ & \\
\hline \multirow{10}{*}{$\begin{array}{c}\text { Working } \\
\text { distance } \\
(\mathrm{m})\end{array}$} & 1.00 & 85.18 & 100 & 100 & 95.56 & 100 & 100 \\
\hline & 1.50 & 71.15 & 100 & 100 & 82.10 & 100 & 100 \\
\hline & 2.00 & $\begin{array}{c}51.29 \\
(46.49) *\end{array}$ & 97.40 & 89.44 & 72.41 & 100 & 100 \\
\hline & 3.00 & & 90.55 & 100 & $\begin{array}{c}46.53 \\
(47.94) *\end{array}$ & 97.95 & 100 \\
\hline & 4.00 & & 74.57 & 90.39 & & 91.01 & 100 \\
\hline & 4.50 & & 76.48 & 90.34 & & 80.75 & 97.97 \\
\hline & 5.00 & & 68.06 & 90.08 & & 73.03 & 98.20 \\
\hline & 5.50 & & 61.30 & 81.15 & & 75.75 & 89.49 \\
\hline & 6.00 & & 55.77 & 73.82 & & 77.98 & 90.45 \\
\hline & 6.50 & & $\begin{array}{c}51.15 \\
(51.45) *\end{array}$ & $\begin{array}{c}75.33 \\
(52.41) *\end{array}$ & & $\begin{array}{c}71.59 \\
(51.94) *\end{array}$ & $\begin{array}{c}91.26 \\
(52.70)\end{array}$ \\
\hline
\end{tabular}

()$^{*}$ Value of PWL-10 at the measurement limit distance.

\subsection{Analysis of the Causes of Crack Measurement Errors}

Previous researchers pointed out that the causes of errors in crack measurement are in the resolution, image processing method, thresholding process during image processing, and mixed-pixel phenomenon, in which the background is recognized as a crack or a crack is recognized as a background [30]. Nevertheless, based on the results obtained in this experiment, it is judged that the errors occur due to the resolution of the imaging equipment and the range of the applied focal length.

Given the basic image processing theory, the smallest unit of digital images is expressed as integers in pixel units [31]. However, in order to accurately measure crack widths, the measured pixel values should be in decimal units, but this is not the case in practice. To help understanding, the measured pixel counts and width values of SC100-0.5 and SC50-0.5 within the same shooting section range among the resulting values derived using SC equipment are shown in Figure 15, where Pm is a pixel value measured through image processing and Pr is a value obtained by dividing the ground truth value by the GSD value according to the working distance applied to each focal length, which can be calculated using Equation (6).

$$
\begin{gathered}
\text { Number of real pixels }=\frac{\text { Ground truth }}{G S D} \\
G S D=\frac{L-f}{f} \times \frac{s_{S}}{s_{R}}
\end{gathered}
$$

$W m$ is an area value in consideration of the GSD value for the number of pixels acquired through image processing. The ground truth is the width value of the virtual image, and it is the area value considering the GSD value for the actual pixel value. In addition, for ease of reading the figure, only the inflection point parts were expressed using markers.

In Figure 15a, it can be seen that PWL-10 values are more precisely measured in the case of SC100-0.5 than SC50-0.5 when the width is measured. Moreover, the position where the measured pixel value and the theoretical actual pixel value intersect was found to be a point with $0 \%$ error, as shown in Table 7. 


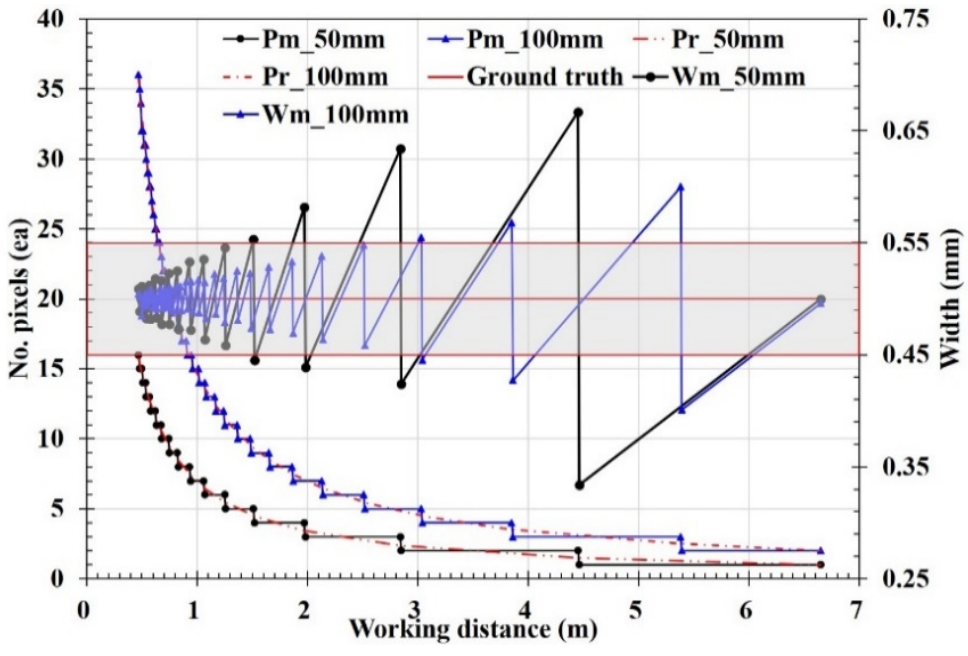

(a) The measured width value

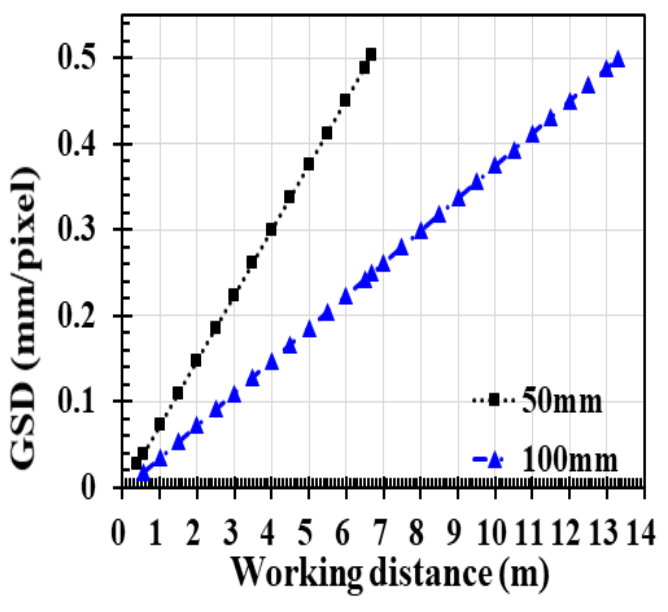

(b) GSD value at $50 \mathrm{~mm}$ and $100 \mathrm{~mm}$

Figure 15. (a) The actual number of pixels of a $0.5 \mathrm{~mm}$ wide virtual image and the measured width value based on the measured pixel value; (b) GSD value at $50 \mathrm{~mm}$ and $100 \mathrm{~mm}$ focal lengths according to working distance.

Table 7. Position of shooting with zero error of measurement width value.

\begin{tabular}{|c|c|c|c|c|}
\hline & & \multicolumn{2}{|c|}{ Working Position $($ Error $=0$ ) } & Unit: mm \\
\hline \multirow{2}{*}{\multicolumn{2}{|c|}{ Classification }} & \multicolumn{3}{|c|}{ Width (mm) } \\
\hline & & $0.1 \mathrm{~mm}$ & $0.3 \mathrm{~mm}$ & $0.5 \mathrm{~mm}$ \\
\hline \multirow{2}{*}{$\begin{array}{l}\text { Focal } \\
\text { length }\end{array}$} & $50 \mathrm{~mm}$ & $490,710,1370$ & $\begin{array}{c}410,490,710,1370 \\
2030,4010\end{array}$ & $\begin{array}{c}490,600,650,710 \\
1150,1700,2250,3350, \\
6650\end{array}$ \\
\hline & $100 \mathrm{~mm}$ & $\begin{array}{c}540,760,980 \\
1420,2740\end{array}$ & $\begin{array}{c}540,760,820,980, \\
1090,1420,2080 \\
2740,4060,8020\end{array}$ & $\begin{array}{c}540,650,700,760,980, \\
1200,1300,1420,1750, \\
2300,2740,3400,4500, \\
6700,13,300\end{array}$ \\
\hline
\end{tabular}

Given the measurement results shown in Table 8, when a focal length of $50 \mathrm{~mm}$ is applied at a $400 \mathrm{~mm}$ point, the pixel value should be 18.85 to become a value of $0.5 \mathrm{~mm}$ width, but in reality, the pixel value measured through image processing was 19. At a working distance of $470 \mathrm{~mm}$, the actual pixel values at focal lengths of $50 \mathrm{~mm}$ and 100 $\mathrm{mm}$ should be 12.69 and 28.08 , respectively, but the values obtained through measurement were 16 and 36, respectively. For example, in the case of a certain section that is from $3000 \mathrm{~mm}$ to $4000 \mathrm{~mm}$, two-pixel values were measured at $50 \mathrm{~mm}$ focal length in the entire section. As can be seen in Figure 15b, the number of pixel values was maintained at two even though the GSD continued. This is judged to be the cause of the changes in the crack value measured in the section. Given these results, it is considered that the errors occur because of the crack value measured in the form of a positive integer rounded to the nearest integer of the actual crack value, the GSD that increases proportionally as the working distance increases, and the repeating number of pixels. Although the resolution, thresholding process during image processing, and mixed pixels are important elements in crack measurement, measured pixel values are considered to have the greatest effects as they affect the entire section, and they are judged to be a limitation in measurement using imaging equipment. 
Table 8. Measured line width $(0.5 \mathrm{~mm})$.

\begin{tabular}{|c|c|c|c|c|c|c|c|c|c|c|c|}
\hline \multirow{3}{*}{$\begin{array}{l}\text { WD } \\
(\mathrm{mm})\end{array}$} & \multicolumn{2}{|c|}{$\begin{array}{c}G S D \\
(\mathrm{~mm} / \mathrm{Pixel})\end{array}$} & \multicolumn{2}{|c|}{$\begin{array}{c}\text { Real } \\
\text { Pixels (ea) }\end{array}$} & \multicolumn{2}{|c|}{$\begin{array}{l}\text { Measured } \\
\text { Pixel (ea) }\end{array}$} & \multicolumn{2}{|c|}{$\begin{array}{c}\text { Measured } \\
\text { Width (mm) }\end{array}$} & \multicolumn{2}{|c|}{$\begin{array}{l}\text { Error } \\
(\%)\end{array}$} & \multirow{3}{*}{$\begin{array}{c}\text { Ground } \\
\text { Truth } \\
\text { (mm) }\end{array}$} \\
\hline & \multicolumn{10}{|c|}{ Focal Length (mm) } & \\
\hline & 50 & 100 & 50 & 100 & 50 & 100 & 50 & 100 & 50 & 100 & \\
\hline 400 & 0.0265 & - & 18.857 & - & 19 & - & 0.504 & - & 0.75 & & \\
\hline 410 & 0.0273 & - & 18.333 & - & 18 & - & 0.491 & - & -1.81 & & \\
\hline 470 & 0.0318 & 0.0145 & 15.714 & 35.675 & 16 & 36 & 0.509 & 0.504 & 1.18 & 0.90 & \\
\hline 480 & 0.0325 & 0.0143 & 15.349 & 34.736 & 15 & 35 & 0.488 & 0.503 & -2.27 & 0.75 & \\
\hline 1000 & 0.0719 & 0.0341 & 6.947 & 14.667 & 7 & 15 & 0.504 & 0.511 & 0.75 & 2.27 & \\
\hline 2000 & 0.1477 & 0.0719 & 3.385 & 6.947 & 3 & 7 & 0.443 & 0.503 & -11.36 & 0.75 & 0.5 \\
\hline 3000 & 0.2234 & 0.1098 & 2.237 & 4.552 & 2 & 5 & 0.447 & 0.549 & -10.61 & 9.85 & \\
\hline 4000 & 0.2992 & 0.1477 & 1.671 & 3.385 & 2 & 3 & 0.598 & 0.443 & 19.70 & -11.36 & \\
\hline 5000 & 0.375 & 0.1856 & 1.333 & 2.694 & 1 & 3 & 0.375 & 0.557 & -25.00 & 11.36 & \\
\hline 6650 & 0.5000 & 0.2481 & 1.000 & 2.015 & 1 & 2 & 0.5 & 0.496 & 0.00 & -0.75 & \\
\hline
\end{tabular}

\section{Width Measurement: Real Crack (Concrete Bridge)}

In this chapter, we investigate the effect of the measured pixels when measuring an actual crack. The cracks at the abutment of a pedestrian bridge were selected as the ground truth due to safety issues during visual inspection. Crack measurement was carried out through visual inspection, and a scale loupe with a magnifying glass of 10X magnification was used to check the width of fine concrete cracks, as shown in Figure 16. Concrete crack images were obtained from a minimum working distance to $2000 \mathrm{~mm}$, at $200 \mathrm{~mm}$ increments. For the analysis of the acquired crack images, the same image processing method as the method used in the indoor experiment was implemented. However, unlike the linear virtual images, the crack images had bad conditions and a texture on the target surface, so preprocessing was performed to remove noise. The preprocessing procedure was to separate the foreground (cracks and noise) from the background by applying adjacency and connectivity conditions on neighboring pixels. The area of the crack and noise was computed and indexed in descending order. As shown in Figure 17, the noise regions were removed, excluding those with the largest area.

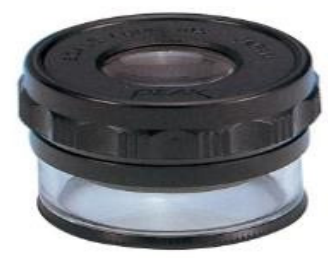

(a) Scale loupe

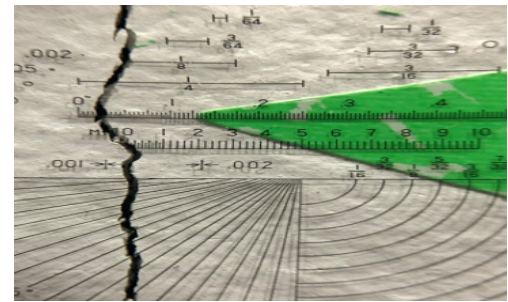

(b) Method of crack measurement

Figure 16. Concrete crack measurement apparatus and method. 


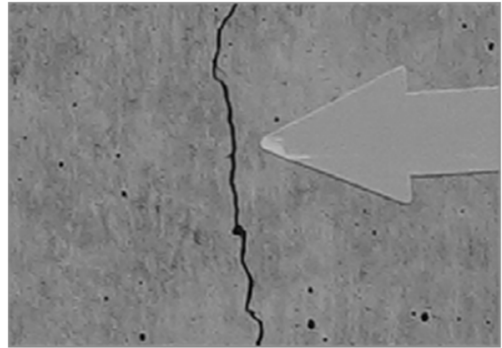

(a) Original image

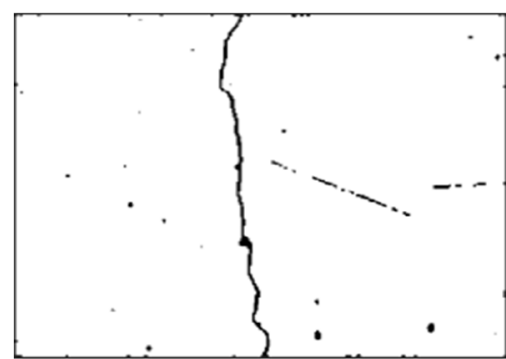

(b) Binary image

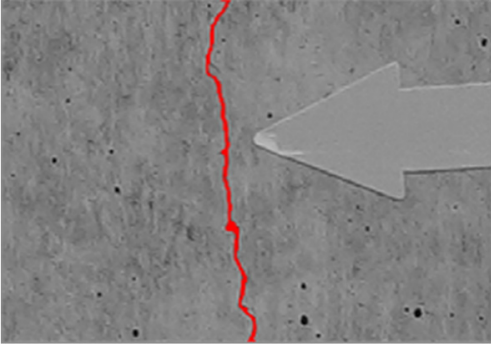

(c) Processed image

Figure 17. Image processing results of concrete crack.

Table 9, and Figures 18 and 19 indicate the number of pixels (Pm), measured crack value $(\mathrm{Wm})$, and errors (Em) according to the width value of the target crack through image processing. In addition, the estimated pixels in Table 9 were derived using the approximation curve in Figure 18 and crack measurement using the estimated pixels illustrated in Figure 19. Regression analysis using the power law was carried out, and the coefficient of determination was 0.9829 . The approximated pixels $(\mathrm{Pa})$, crack width (Wa), and error (Ea) were the calculated crack width and errors according to the working distance, respectively. Here, Pa showed a similar tendency to the pixel Pr corresponding to the actual crack. Moreover, the Wa calculated by the estimated pixel indicated an error of up to $5 \%$ and a great agreement with the ground truth. However, the biggest Em was $19.32 \%$ at the working distance of $1800 \mathrm{~mm}$, while the rest of them were less than $10 \%$. As the working distance increased, the Wm did not show a clear trend in error change and repeated the absolute increase or decrease, because the Pm was measured somewhat higher or lower than the value of Pa or Pr. As mentioned in Section 4.3, in order to accurately measure crack width, the Pm must be in decimal units. However, the Pm was computed as an integer, and it was found that the difference between Pm and Pr led to an error in the crack measurement. In addition, it can be seen that Pr becomes 3 at the position of $1450 \mathrm{~mm}$ where the Pm, Pr, and Pa intersect in Figure 18. Moreover, it can be seen that the measurement error at the same working distance represents positive or negative values, as shown in Table 9. As shown in Table 9 and Figure 18, it was indicated that the error increased as the distance increased, moving away from the reference position. In summary, it was judged that the pixel measured as an integer and the same pixel within a specific working distance range was the cause of the error in the crack measurement. From this evaluation, it was confirmed that the number of pixels corresponding to the working distance had a great influence on the measurement accuracy of crack width when using image processing. Once the working distance is accurately defined, it is judged that the number of pixels measured at each shooting location can be identified through the approximation method.

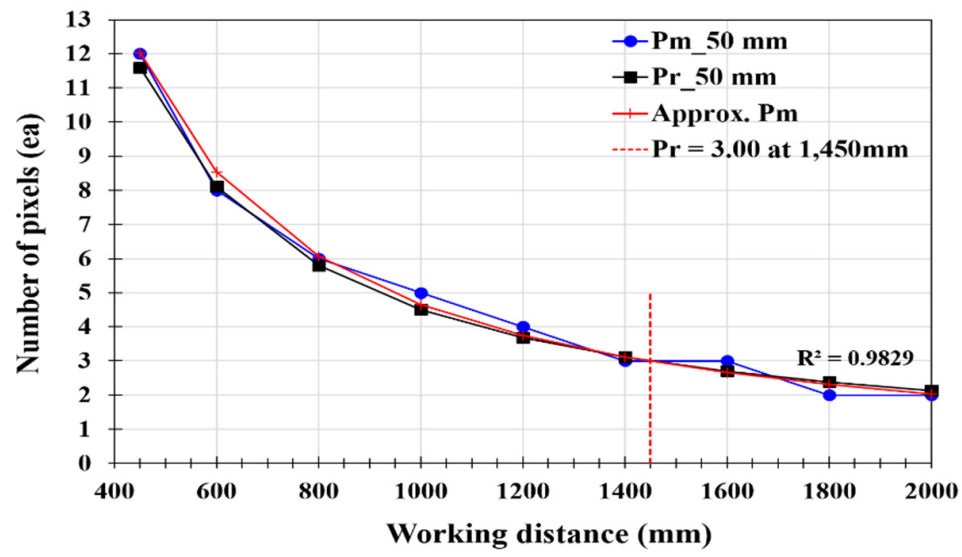

Figure 18. Measured pixels and approximation curves of number of pixels. 
Table 9. GSD and crack width $(0.308 \mathrm{~mm})$.

\begin{tabular}{|c|c|c|c|c|c|c|c|c|c|}
\hline \multirow[b]{2}{*}{$\begin{array}{l}\text { WD } \\
(\mathrm{mm})\end{array}$} & \multirow[b]{2}{*}{$\begin{array}{c}G S D \\
(\mathrm{~mm} / \text { pixel) }\end{array}$} & \multicolumn{3}{|c|}{ Measured } & \multicolumn{3}{|c|}{ Approx. } & \multicolumn{2}{|c|}{ Real } \\
\hline & & $\begin{array}{l}\text { Pm } \\
\text { (ea) }\end{array}$ & $\begin{array}{l}\text { Wm } \\
(\mathrm{mm})\end{array}$ & $\begin{array}{l}\text { Em } \\
(\%)\end{array}$ & $\begin{array}{l}\mathrm{Pa} \\
\text { (ea) }\end{array}$ & $\begin{array}{c}\mathrm{Wa} \\
(\mathrm{mm})\end{array}$ & $\begin{array}{c}\mathrm{Ea} \\
(\%)\end{array}$ & $\begin{array}{l}\operatorname{Pr} \\
\text { (ea) }\end{array}$ & $\begin{array}{c}\text { Ground } \\
\text { Truth } \\
\text { (mm) }\end{array}$ \\
\hline 450 & 0.0265 & 12 & 0.318 & 3.40 & 12.03 & 0.319 & 3.65 & 11.59 & \multirow{9}{*}{0.308} \\
\hline 600 & 0.0379 & 8 & 0.303 & -1.42 & 8.54 & 0.324 & 5.00 & 8.11 & \\
\hline 800 & 0.0531 & 6 & 0.318 & 3.40 & 6.06 & 0.322 & 4.41 & 5.80 & \\
\hline 1000 & 0.0683 & 5 & 0.341 & 9.84 & 4.65 & 0.317 & 3.02 & 4.51 & \\
\hline 1200 & 0.0835 & 4 & 0.334 & 7.79 & 3.74 & 0.312 & 1.41 & 3.69 & \\
\hline 1400 & 0.0987 & 3 & 0.296 & -4.02 & 3.11 & 0.307 & 0.24 & 3.12 & \\
\hline 1600 & 0.1139 & 3 & 0.341 & 9.84 & 2.66 & 0.302 & 1.85 & 2.70 & \\
\hline 1800 & 0.1291 & 2 & 0.258 & -19.32 & 2.31 & 0.297 & 3.40 & 2.39 & \\
\hline 2000 & 0.1442 & 2 & 0.288 & -6.76 & 2.04 & 0.293 & 4.88 & 2.14 & \\
\hline
\end{tabular}

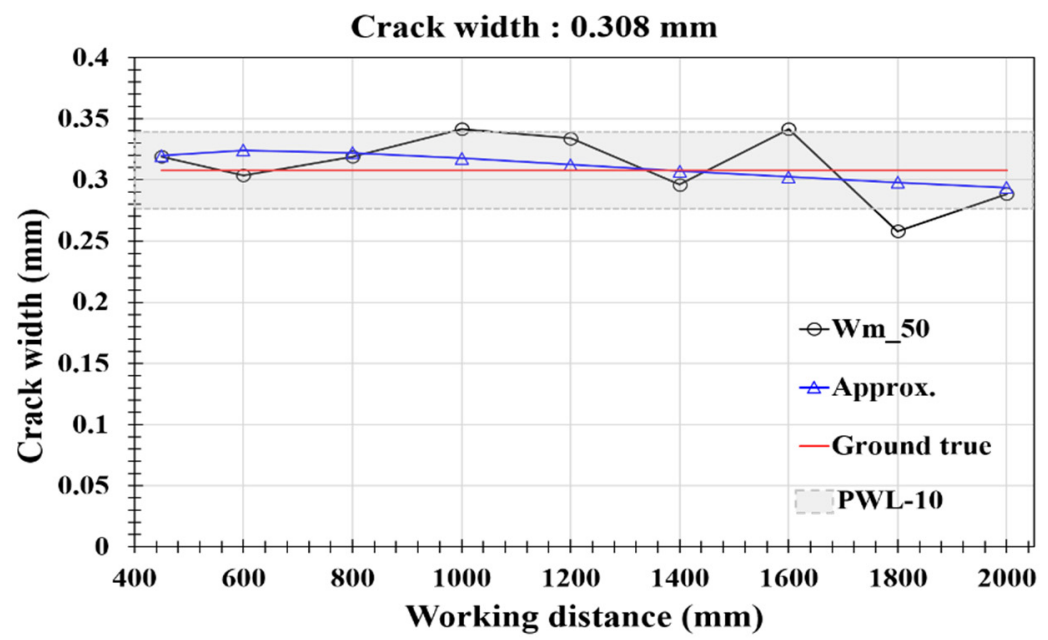

Figure 19. Measurement results of concrete crack.

\section{Conclusions}

In this paper, indoor measurement experiments were conducted to measure cracks in concrete structures and to present guidelines for image acquisition and processing using imaging equipment. Two units of DSLR imaging equipment, which is applied in various fields, were selected, and lenses with focal lengths of 50,100, and $135 \mathrm{~mm}$ were applied. Linear virtual images with widths of $0.1,0.3$, and $0.5 \mathrm{~mm}$ were applied to the indoor measurement experiments, and video images were obtained at $10 \mathrm{~mm}$ intervals from the minimum working distance to the measurement limit distance to measure the line width values of the virtual images through image processing. The crack measurement limits, as well as optimal working distances of the selected imaging equipment and optical equipment, were derived to analyze measurement accuracy according to the difference in resolution and focal lengths. Field measurement tests were conducted to verify measurement parameters identified by the results of the indoor experiment. The conclusions drawn from this study are as follows.

- The pixel values were measured using the CC (Canon camera) and SC (Sony camera) equipment units with performances of 22.1 and 61 million pixels, respectively, and applying the same focal lengths. The SC equipment had 2.76 times higher resolution corresponding to the sensor area and 1.65 times larger horizontal and vertical dimensions than the CC equipment, respectively. As a result of applying the same 
focal length, it was found that the measured number of pixels and the measurement limit distance increased because the resolution and size of the virtual image increased. However, despite an increase in resolution by 1.65 times, the measured pixel values of the SC50 were estimated to be 1.33, 1.10, and 1.19 times higher, respectively, than the CC50 at the minimum working distance. In addition, when the virtual image size increased by three times from 0.1 to $0.3 \mathrm{~mm}$, the pixel value of CC50 at the minimum working distance increased by 3.3 times, and when it increased by five times from $0.1 \mathrm{~mm}$ to $0.5 \mathrm{~mm}$, the pixel value increased by 5.5 times. As for SC50, the pixel value increased by 2.75 times and 4.75 times, respectively.

- As for increasing the focal length at the same resolution, the value showed a similar tendency with the results of increasing the resolution. However, the pixel value of SC100 was 1.85 times larger at average than that of SC50 at the minimum working distance. When the size of the virtual image increased by three times and by five times, the pixel value of SC100 was estimated at the same rate and by 5.13 times. As a result of experiments, the pixel value was more affected by the increase in focal length than the increase in resolution. However, even if the resolution, focal length, and size of the object increased, the pixel values did not increase at the same rate. It is considered that the difference between the pixel value and the rate could occur because of the minimum working distance, in accordance with the physical features of an optical lens.

- According to the results, in the case of CC50-0.1 and SC50-0.1 mm, 39.29\% and 38.77\% of the working positions, respectively, had values within PWL-10 within the respective measurement limit distances. With regard to the $0.3 \mathrm{~mm}$ wide virtual image, 48.61 and $49.17 \%$, respectively, of the working positions had values within PWL-10. For the $0.5 \mathrm{~mm}$ virtual image, 50.26 and $51.44 \%$, respectively, of the working positions had values within PWL-10 within the limit distance. There was no significant difference in measurement accuracy within the limit distance of the imaging equipment. However, relative comparisons by shooting section showed that the SC equipment had somewhat higher precision than the CC equipment.

- Increasing the focal length enables more precise measurement by increasing the measurement limit distance and pixel measurement values, as well as reducing the GSD value of imaging equipment. When measurement accuracy was checked by section while increasing the working distance from the minimum working distance, it was found that within a $1 \mathrm{~m}$ working distance, with regard to SC50-0.1 and SC100-0.1, 39.34 and $85.18 \%$ of working positions, respectively, had values within PWL-10, and as for SC135-0.1, 95.55\% of working positions had values within PWL-10. In the case of SC50-0.3, the ratio was $96.72 \%$ within $1 \mathrm{~m}$ of the working distance, and for SC100-0.3 and SC135-0.3, all working positions within working distances of $1.5 \mathrm{~m}$ and $2 \mathrm{~m}$, respectively, had values within PWL-10. In the case of SC50-0.5, all working positions within a working distance of $1.5 \mathrm{~m}$ had values within PWL-10, and as for SC100-0.5 and SC135-0.5, all working positions within working distances of $3 \mathrm{~m}$ and 4 $\mathrm{m}$, respectively, had values within PWL-10. Based on the results of analysis of PWL-10 in this study, cracks were measured using a unit of 61-megapixel imaging equipment, and according to the results, in the case of $0.3 \mathrm{~mm}$ wide or wider cracks, a working distance of $1 \mathrm{~m}$ was secured when the focal length was $50 \mathrm{~mm}$, and working distances of 3 and $4 \mathrm{~m}$ were secured when the focal lengths were 100 and $135 \mathrm{~mm}$, respectively. However, with regard to cracks not wider than $0.1 \mathrm{~mm}$, focal lengths of 100 and $135 \mathrm{~mm}$ showed measurability within $1 \mathrm{~m}$, but a focal length of $50 \mathrm{~mm}$ was judged to hardly enable measurement, except for certain working positions.

- Many elements affect width measurement. However, based on the results of this study, width measurement is highly dependent on the measured pixel values. In order to accurately measure width, the measured pixel values must be in decimal units, but that is theoretically impossible. Field measurement tests were conducted to verify measurement parameters identified by the results of the indoor experiment. An 
approximate curve was predicted based on the pixel value according to the working distance, and an estimated pixel value was derived using power law distribution. As the working distance increased, the crack measurement value $(\mathrm{Wm})$ did not show a clear trend in error change and fluctuated with ground truth. However, the crack width (Wa) calculated by the estimated pixel indicated an error of up to $5 \%$ and showed great agreement with the ground truth. From the evaluation, it was confirmed that the number of pixels corresponding to the working distance had a great influence on the measurement accuracy of crack width when using image processing. Once the working distance is accurately defined, it is judged that the number of pixels measured at each shooting location can be identified through the approximation method.

- If microcracks not wider than $0.1 \mathrm{~mm}$ are measured by applying imaging equipment with the same resolution as applied in this experiment and a focal length of $50 \mathrm{~mm}$, the measurement should be carried out at distances shorter than the minimum working distance from the crack surface. To secure at least $90 \%$ measurement accuracy for widths not larger than $0.1 \mathrm{~mm}$ at working distances not longer than $1 \mathrm{~m}$, a focal length of $135 \mathrm{~mm}$ should be applied. In addition, the resolution value required when a focal length of $50 \mathrm{~mm}$ is applied was estimated using the GSD value calculated by applying a focal length of $135 \mathrm{~mm}$, and according to the results, it is thought that the resolution range of the imaging equipment should be at least about 400 million pixels.

Author Contributions: Conceptualization, H.J. and D.C.; methodology, H.J., B.J., M.H. and D.C.; software, H.J. and M.H.; validation, H.J. and D.C.; formal analysis, H.J. and D.C.; investigation, H.J. and M.H.; resources, D.C.; data curation, B.J. and M.H.; writing-original draft preparation, H.J.; writing - review and editing, H.J. and D.C.; supervision, D.C.; project administration, D.C. All authors have read and agreed to the published version of the manuscript.

Funding: This research received no external funding.

Institutional Review Board Statement: Not applicable.

Informed Consent Statement: Not applicable.

Data Availability Statement: The data presented in this study are included within the article.

Conflicts of Interest: The authors declare no conflict of interest.

\section{References}

1. Mohan, A.; Poobal, S. Crack detection using image processing: A critical review and analysis. Alex. Eng. J. 2018, 57, 787-798. [CrossRef]

2. Zakeri, H.; Nejad, F.M.; Fahimifar, A. Image Based Techniques for Crack Detection, Classification and Quantification in Asphalt Pavement: A Review. Arch. Comput. Methods Eng. 2016, 24, 935-977. [CrossRef]

3. Koch, C.; Georgieva, K.; Kasireddy, V.; Akinci, B.; Fieguth, P. A review on computer vision based defect detection and condition assessment of concrete and asphalt civil infrastructure. Adv. Eng. Inform. 2015, 29, 196-210. [CrossRef]

4. Lee, B.Y.; Kim, Y.Y.; Yi, S.T.; Kim, J.K. Automated image processing technique for detecting and analyzing concrete surface cracks. Struct. Infrast. Eng. 2013, 9, 567-577. [CrossRef]

5. Naidoo, T.; Joubert, D.; Chiwewe, T.; Tyatyantsi, A.; Rancati, B.; Mbizeni, A. Visual surveying platform for the automated detection of road surface distresses. In Proceedings of the SPIE The International Society for Optical Engineering, Kruger National Park, Skukuza, South Africa, 23 June 2014.

6. Huang, J.; Liu, W.; Sun, X. A Pavement Crack Detection Method Combining 2D with 3D Information Based on Dempster-Shafer Theory. Comp. Aided Civil Infrast. Eng. 2014, 29, 299-313. [CrossRef]

7. Mathavan, S.; Kamal, K.; Rajman, M. A Review of Three-Dimensional Imaging Technologies for Pavement Distress Detection and Measurements. IEEE Trans. Int. Trans. Syst. 2015, 16, 2353-2362. [CrossRef]

8. Guan, H.; Li, J.; Yu, Y.; Chapman, M.; Wang, C. Automated Road Information Extraction from Mobile Laser Scanning Data. IEEE Trans. Int. Trans. Syst. 2015, 16, 194-205. [CrossRef]

9. Otsu, N. A Threshold Selection Method from Gray-Level Histograms. IEEE Trans. Syst. Man Cybern. 1979, 9, 62-66. [CrossRef]

10. Ito, A.; Aoki, Y.; Hashimoto, S. Accurate extraction and measurement of fine cracks from concrete block surface image. In Proceedings of the IEEE 2002 28th Annual Conference of the Industrial Electronics Society, Seville, Spain, 5-8 November 2002.

11. Fujita, Y.; Mitani, Y.; Hamanoto, Y. A Method for Crack Detection on a Concrete Structure. In Proceedings of the 18th International Conference on Pattern Recognition, Hong Kong, China, 20-24 August 2006. 
12. Oliveira, H.; Correia, P.L. Automatic crack detection on road imagery using anisotropic diffusion and region linkage. In Proceedings of the 2010 18th European Signal Processing Conference, Aalborg, Denmark, 23-27 August 2010.

13. Zhang, W.; Zhang, Z.; Qi, D.; Liu, Y. Automatic Crack Detection and Classification Method for subway Tunnel Safety Monitoring. Sensors 2014, 14, 19307-19328. [CrossRef]

14. Sinha, S.K.; Fieguth, P.W. Automated detection of cracks in buried concrete pipe images. Autom. Constr. 2006, 15, 58-72. [CrossRef]

15. Merazi-Meksen, T.; Boudraa, M.; Boudraa, B. Mathematical morphology for TOFD image analysis and automatic crack detection. Ultrasonics 2014, 54, 1642-1648. [CrossRef]

16. Su, T.C. Application of Computer Vision to Crack Detection of Concrete Structure. IACSIT Int. J. Eng. Technol. 2013, 5, 457-461. [CrossRef]

17. Zhao, H.; Qin, G.; Wang, X. Improvement of canny algorithm based on pavement edge detection. In Proceedings of the 2010 3rd International Congress on Image and Signal Processing, Yantai, China, 16-18 October 2010.

18. Wang, G.; Tse, P.W.; Yuan, M. Automatic internal crack detection from a sequence of infrared images with a triple-threshold Canny edge detector. Meas. Sci. Technol. 2017, 29, 025403. [CrossRef]

19. Lee, H.B.; Kim, J.W.; Jang, I.Y. Development of Automatic Crack Detection System for Concrete Structure Using Image Processing Method. J. Kor. Inst. Struct. Maint. Insp. 2012, 16, 64-77.

20. Li, G.; He, S.; Ju, Y.; Du, K. Long-distance precision inspection method for bridge cracks with image processing. Autom. Constr. 2014, 41, 83-95. [CrossRef]

21. Jahanshahi, M.R.; Masri, S.F. Adaptive vision-based crack detection using 3D scene reconstruction for condition assessment of structures. Autom. Constr. 2012, 22, 567-576. [CrossRef]

22. Jahanshahi, M.R.; Masri, S.F.; Padgett, C.W.; Sukhantme, G.S. An innovative methodology for detection and quantification of cracks through incorporation of depth perception. Mach. Vis. Appl. 2013, 24, 227-241. [CrossRef]

23. Lins, R.G.; Givigi, S.N. Automatic crack detection and measurement based on image analysis. IEEE Trans. Instrum. Meas. 2016, 65, 583-590. [CrossRef]

24. Khalili, K.; Vahidnia, M. Improving the accuracy of crack length measurement using machine vision. In Proceedings of the 8th International Conference Interdisciplinarity in Engineering, INTER-ENG 2014, Tigru Mures, Romania, 9-10 October 2014.

25. Bhowmick, S.; Nagarajaisa, S.; Veeraraghavan, A. Vision and deep learning-based algorithms to detect and quantify cracks on concrete surfaces from UAV videos. Sensors 2020, 20, 6299. [CrossRef] [PubMed]

26. Kim, J.W.; Kim, S.B.; Park, J.C.; Nam, J.W. Development of crack detection system with unmanned aerial vehicles and digital image processing. In Proceedings of the 2015 World Congress on Advances in Structural Engineering and Mechanics (ASEM15), Incheon, Korea, 25-29 August 2015.

27. Li, S.; Zhao, X. Automatic crack detection and measurement of concrete structure using convolutional encoder-decoder network. IEEE Access 2020, 8, 134602-134618. [CrossRef]

28. Feng, C.; Zhang, U.; Wang, H.; Wang, S.; Li, Y. Automatic pixel-level crack detection on dam surface using deep convolutional network. Sensors 2020, 20, 2069. [CrossRef] [PubMed]

29. Feng, D.; Feng, M.Q.; Ozer, E.; Fukuda, Y. A Vision-Based Sensor for Noncontact Structural Dispacement Measurement. Sensors 2015, 15, 16557-16575. [CrossRef] [PubMed]

30. Cho, H.W. A Study on Image Based Crack Measurement Using Crack Width Transform Method. Ph.D. Thesis, University of Science and Technology, Deaejon, Korea, 2018.

31. Gonzalez, R.C.; Woods, R.E. Digital Image Processing, 3rd ed.; Pearson Education: Upper Saddle River, NJ, USA, 2008. 